\title{
Inception of subsequent stepped leaders in negative cloud-to-ground lightning
}

\author{
Maribeth Stolzenburg ${ }^{1}$ (D) Thomas C. Marshall $^{1} \cdot$ Sumedhe Karunarathne ${ }^{2}$
}

Received: 5 May 2019 / Accepted: 11 October 2019 / Published online: 30 October 2019

(c) The Author(s) 2019

\begin{abstract}
Time-correlated high-speed video and electric field change data for 139 natural, negative cloud-to-ground (CG)-lightning flashes reveal 615 return strokes (RSs) and 29 upward-illumination (UI)-type strokes. Among 121 multi-stroke flashes, 56\% visibly connected to more than one ground location for either a RS or UI-type stroke. The number of separate ground-stroke connection locations per CG flash averaged 1.74, with maximum 6. This study examines the 88 subsequent strokes that involved a subsequent stepped leader (SSL), either reaching ground or intercepting a former leader to ground, in 61 flashes. Two basic modes by which these SSLs begin are described and are termed dart-then-stepped leaders herein. One inception mode occurs when a dart leader deflects from the prior main channel and begins propagating as a stepped leader to ground. In these 'divert' mode cases, the relevant interstroke time from the prior RS in the channel to the SSL inception from that path is long, ranging from 105 to $204 \mathrm{~ms}$ in four visible cases. The alternative mode of SSL inception occurs when a dart leader reaches the end of a prior unsuccessful branch —of an earlier competing dart leader, stepped leader, or initial leader-then begins advancing as a stepped leader toward ground. In this more common 'branch' mode ( $85 \%$ of visible cases), there may be no portion of the subsequent RS channel that is shared with a prior RS channel. These two inception modes, and variations among them, can occur in different subsequent strokes of the same flash.
\end{abstract}

\section{Introduction}

Negative cloud-to-ground (CG) lightning often exhibits multiple ground connections for a single flash or for a single stroke. First strokes, especially, may include branched or forked connections to ground (e.g., Ballarotti et al. 2005) occurring within a few tens of microseconds of the main return stroke (RS). Some RSs may be followed, within several hundred microseconds, by upward-illumination (UI)type minor strokes (e.g., Stolzenburg et al. 2012, 2013a) which have different ground connection locations. In flashes with multiple RSs, it is relatively common for subsequent strokes (those after the first RS) to connect in a new ground location. For example, Rakov et al. (1994) found $25 \%$ of 155 strokes of order second through fourth terminated in

Responsible Editor: S. W. Kim.

Maribeth Stolzenburg

mstolzen@phy.olemiss.edu

1 Department of Physics and Astronomy, University of Mississippi, University, MS, USA

2 Baptist College of Health Sciences, Memphis, TN, USA a location different from that of a prior stroke. The present study focuses on this last category of flashes with more than one RS ground connection location.

Malan and Schonland (1951) have suggested that multiple return strokes in a single flash may be caused by channel "cutoff", or a loss of channel conductivity, at some location along the original return stroke path. Two different mechanisms have been proposed to explain cutoff. One mechanism is based on laboratory measurements of electrical arcs in the air which indicate that a lightning channel may have a "negative differential resistance", such that if return stroke current falls below about $100 \mathrm{~A}$, the channel resistance will rapidly increase and drive the current to zero (Heckman 1992; Williams 2006; Williams and Heckman 2012). The other mechanism is based on the screening effect of channel branching (Mazur and Ruhnke 1993, 2014); in this mechanism, some leader branches shield other branches from the large ambient electric field, thereby causing the shielded branches to stop extending.

The prevailing understanding of subsequent strokes is that they begin with a dart or dart-stepped leader traveling in a previously ionized channel. For the purposes of this work, we will not be concerned with the important differences 
between dart and dart-stepped leaders (e.g., Krider et al. 1977); herein, we will refer to leaders that travel along previous paths as dart leaders. In typical multi-stroke flashes, the dart leader travels entirely within a prior RS channel; hence, the typical subsequent RS has the same ground location as the prior RS. However, it is not unusual in multiple RS flashes for at least one subsequent stroke to connect in a different ground location. Subsequent RSs with a new ground location involve a subsequent stepped leader (SSL) to ground. Rakov and Uman (2003) describe new ground connections in subsequent strokes as occurring when dart leaders "deflect from the previous return stroke path, become stepped leaders, and form a new termination on ground". Recently, another mode of producing an SSL that travels to ground has been shown in Stolzenburg et al. (2013b) (their Figs. 7, 14, 4), Stolzenburg et al. (2014) (their Figs. 15, 16), Campos et al. (2014) (their Case 5), and Stolzenburg et al. (2015) (their Fig. 4). In this other mode, dart leader travels along a prior branch that did not reach the ground; when the dart leader reaches the end of that branch, it becomes a stepped leader. Part of the motivation for the current work is to investigate both modes more fully and to determine their relative occurrence rates across a large video data set.

In this study, we examine dart leader and stepped leader propagation prior to subsequent RSs that connect to new ground locations. Using high-speed video data, it is straightforward to distinguish between a negative stepped leader and a dart leader, because they appear with distinctly different propagation characteristics. Electric field change (E-change) data also reveal different pulse characters for dart leaders and stepped leaders (e.g., Krider et al. 1977; Rakov and Uman 2003; Stolzenburg et al. 2013b), and multi-station E-change data are used in this work to support the optical analysis. This study confirms that there are two modes in which SSLs begin, and we find the more common mode is that in which the dart leader travels along a prior unsuccessful branch then becomes a stepped leader from the end of that branch. Knowing the modes in which SSLs occur can inform future work to determine why a prior RS channel is not always followed in subsequent strokes.

\section{Data sources}

The data for this study were acquired near Cape Canaveral, Florida, in July and August, 2011. A Vision Research Phantom ${ }^{\circledR}$ v12.1 camera with $8 \mathrm{~mm}$ lens was used, usually at a capture rate of 50,000 frames per second $(52,500 \mathrm{fps}$ was used on 1 day) and $320 \times 240$ (pixels) image resolution. Ground level (horizon) in these data is close to or at sea level. Electric field change (E-change) data were acquired at 5 megasamples per second with a ten-station array of slow and fast antennas. Source locations for some E-change pulses were determined using a time-of-arrival technique called PBFA (Karunarathne et al. 2013), and locations of some VHF sources were available from the LDAR2 system (Murphy et al. 2008) at Kennedy Space Center. A full description of the data sources can be found in Stolzenburg et al. (2013a, 2014), Karunarathne et al. (2013) and Marshall et al. (2014).

In keeping with earlier work (Stolzenburg et al. 2012, 2013a), UI-type strokes are not considered as regular return strokes herein and are tabulated separately (in Sect. 3). These strokes, occurring within a few milliseconds after a return stroke, have apparently weak or no connection with the incloud leader/channel system at the time of the main RS. For the purposes of this study, UI-type strokes are counted separately, because they are considered to include a competing stepped leader that develops concurrently with the main stepped leader, rather than a subsequent stepped leader that develops separately after a stroke. There are 26 flashes with 30 visible UI-type strokes in the full set of 149 complete and partially captured CG flashes used in this work.

\section{SSL statistics}

As summarized in Table 1, the high-speed video data set examined for this study includes 139 complete CG flashes having 615 RSs and 29 UI-type strokes. The average multiplicity is 4.4 return strokes per flash, while the average including UI-type strokes is 4.6 strokes per flash. Single RS flashes (15\% of flashes) are about as frequent in our data as the lowest values of $15-35 \%$ found previously by numerous investigators (e.g., Kitagawa et al. 1962; Anderson and Eriksson 1980; Rakov et al. 1994; Saba et al. 2006) for negative CG flashes in various parts of the world. However, only $18(13 \%)$ of our flashes exhibited a single stroke, since 3 flashes with a single RS also had a UI-type stroke within $2 \mathrm{~ms}$ of the RS. The maximum number of RSs per flash is 15 , and the median is 4 . Our multiplicity average is within the typical range of 3-5 (e.g., Rakov and Uman 2003) and is the same as that found for 76 flashes in Florida by Rakov and Uman (1990).

Table 1 also categorizes the set of flashes according to the number of separate RS ground connection locations (GLs). In the 139 flashes, there are 221 distinct GLs for the 615 RSs. (Another 23 GLs of UI-type strokes are not used by any RS of their flash.) Thus, the average number of separate RS GLs per flash in this data set is 1.59 and the maximum is 5; with UI-type strokes included the average and maximum values are 1.74 and 6 GLs per flash. Overall, $41 \%$ of our 139 CG flashes and $48 \%$ (57) of the 118 multiple RS flashes connect to more than one location for a return stroke. These percentages are similar to prior studies that have found up to $51 \%$ of multiple RS flashes with more than one ground 
Table 1 Return strokes and ground locations per flash in high-speed video data

\begin{tabular}{|c|c|c|c|c|c|c|c|c|c|}
\hline \multirow[t]{2}{*}{ Number of RSs } & \multirow[t]{2}{*}{$\%$ Total flashes } & \multicolumn{5}{|c|}{ RS ground locations, GLs } & \multicolumn{2}{|c|}{ UI-type strokes ${ }^{\mathrm{a}}$} & \multirow[t]{2}{*}{ Maximum GLs } \\
\hline & & One & Two & Three & Four & Five & One & Two & \\
\hline 1 & $15.1 \%$ & 21 & - & - & - & - & 3 & & Two \\
\hline 2 & $11.5 \%$ & 9 & 7 & - & - & - & 2 & & Three \\
\hline 3 & $15.8 \%$ & 9 & 10 & 3 & - & - & 3 & 1 & Four \\
\hline 4 & $18.7 \%$ & 15 & 9 & 1 & 1 & - & 4 & 2 & Five \\
\hline 5 & $13.7 \%$ & 10 & 6 & 1 & 2 & 0 & 3 & & Five \\
\hline 6 & $4.3 \%$ & 3 & 0 & 2 & 1 & 0 & 0 & & Four \\
\hline 7 & $7.2 \%$ & 7 & 3 & 0 & 0 & 0 & 3 & 1 & Three \\
\hline 8 & $3.6 \%$ & 2 & 1 & 1 & 0 & 1 & 0 & & Five \\
\hline 9 & $3.6 \%$ & 2 & 1 & 1 & 0 & 1 & 2 & & Six \\
\hline 10 & $2.2 \%$ & 1 & 1 & 1 & 0 & 0 & 1 & & Three \\
\hline 11 & $1.4 \%$ & 2 & 0 & 0 & 0 & 0 & & & One \\
\hline 12 & $0.7 \%$ & 0 & 1 & 0 & 0 & 0 & & & Two \\
\hline 13 & $0.7 \%$ & 1 & 0 & 0 & 0 & 0 & & & One \\
\hline 14 & $0.7 \%$ & 0 & 1 & 0 & 0 & 0 & & & Two \\
\hline 15 & $0.7 \%$ & 0 & 0 & 1 & 0 & 0 & & & Three \\
\hline \#Flashes & 139 & 82 & 40 & 11 & 4 & 2 & 21 & 4 & \\
\hline$\%$ of Total & & $59.0 \%$ & $28.8 \%$ & $7.9 \%$ & $2.9 \%$ & $1.4 \%$ & & & \\
\hline Averages & $\begin{array}{l}\text { RSs per flash } \\
\text { RS GLs per flash }\end{array}$ & & & $\begin{array}{l}4.4 \\
1.58\end{array}$ & $\begin{array}{l}\mathrm{RS}+ \\
\mathrm{RS}+\end{array}$ & $\begin{array}{l}\text { sh } \\
\text { r flash }\end{array}$ & & $\begin{array}{l}4.6 \\
1.74\end{array}$ & \\
\hline
\end{tabular}

${ }^{\mathrm{a}}$ Upward illumination (UI-type) strokes have a separate ground connection location from their accompanying RS

connection point (e.g., Kitagawa et al. 1962; Rakov et al. 1994; Willett et al. 1995; Valine and Krider 2002; Qie et al. 2005; Saba et al. 2006). With UI-type strokes included, $49 \%$ of the flashes and $56 \%$ of the 121 multi-stroke flashes visibly connect to more than one GL. (These values do not include GLs used only in "fork" or downward branch connections to ground during strokes, which typically occur only with strokes involving a stepped leader to ground.)

Of interest for this study, there are 488 usable subsequent return strokes in our video data set. Among these, 82 are immediately preceded by stepped leaders (SSLs) to ground, as evidenced in the video data by their different ground connection points relative to any prior strokes. There are 6 additional known cases of subsequent stepped leaders that intercept a former channel to ground, then become successful dart leaders (i.e., stepped-to-dart leaders, as in Stolzenburg et al. 2013b) and RSs to a formerly used ground connection. Thus, at least $18 \%$ of the subsequent strokes in our data involve a stepped leader. The 88 strokes involving SSLs occur in 61 flashes (about half of the 118 multi-stroke CGs), spread across all 13 days of video data collection. Examples are shown in Sect. 4. Notably, 18 flashes have two or more SSL strokes, including 5 flashes with three SSL strokes and 2 flashes with four strokes involving SSLs. One flash of this last group is the subject of Sect. 5 .

A histogram of the 88 SSL strokes according to their stroke order is shown in Fig. 1a. In the 118 multiple RS flashes, 35.6\% (42) of second strokes involve a stepped leader. Clearly, Fig. 1a shows that the likelihood of a particular stroke being an SSL decreases markedly with stroke order. For example, among the 80 multi-RS flashes having a 4th stroke, only $17.5 \%$ (14) of those strokes were SSLs. This is in addition to the basic decreasing likelihood of a CG flash in the data set having each higher stroke order. Figure $1 \mathrm{~b}$ shows that stroke orders higher than 2 nd account for $46(52 \%)$ of the SSL strokes, including 6 that are fifth RSs and 1 that is a sixth RS. Overall, $27 \%$ of our 300 RSs of order 2nd-4th involve an SSL, and all but 5 of those connected in a different location from a prior stroke. These values are quite similar to those found by Rakov et al. (1994), in which $37 \%$ (23) of second-order RSs, and $25 \%$ of $155 \mathrm{RSs}$ of order 2nd -4 th connected to a location different from that of a prior stroke.

As mentioned in the Introduction and shown in the following sections, we find two modes in which SSLs begin. Both these modes are preceded by dart leaders. The SSL inceptions essentially separate into those in which the successful dart leader propagates in but diverts from a prior RS main channel, and those in which the successful dart leader follows a prior branch (rather than the main channel) before becoming a stepped leader. In 26 of the 88 cases, the video data clearly show the SSL inception mode; the transition to stepped leader is apparent, along with many of the leaders, branches, and main RS channels of earlier strokes. 
Fig. 1 a Occurrence likelihood of a CG flash in the video data set having a stroke of order 2 nd through 6th (green markers), and percentage of strokes in multiple RS flashes in which each stroke order involves a stepped leader (grey bars). Data set has 139 complete flashes and 118 multi-RS flashes. b Histogram of stroke order for 88 subsequent stepped leaders, categorized by inception mode, as determined from video data. Total number of subsequent strokes is 488. c Distribution of preceding interstroke intervals for all negative subsequent strokes and subset of SSL strokes for 118 flashes in Florida. (One ISI value, $716.97 \mathrm{~ms}$, not shown.) Modal bin is 10-ms range with largest count (54). Lighter shading emphasizes bin size change (to $60 \mathrm{~ms}$ ) at $180 \mathrm{~ms}$. The 12 ISI values greater than $308 \mathrm{~ms}$ are statistical outliers $(>3$ std dev from mean)
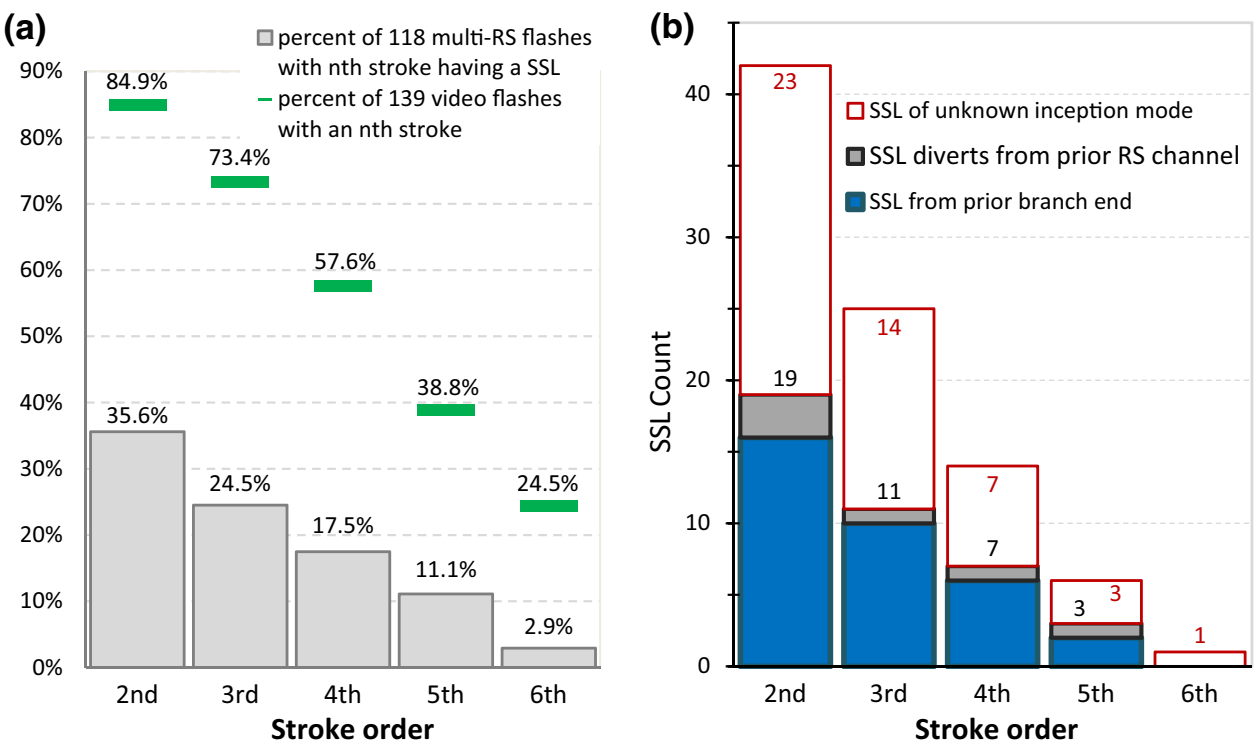

These features provide visible evidence which allows us to identify overlapping and re-used portions in subsequent strokes. In another 14 cases, the SSL inception mode can be deduced based on video evidence-such as channel overlap, proximity to former branches, and luminosity at the dart leader's beginning - although the leaders and branches are not entirely visible. For the remaining 48 strokes involving SSLs, the subsequent leader either appears first as a stepped leader that travels to ground or is too dim to distinguish until the RS occurs. Thus, the SSL inception mode is unknown from the video data in these cases.

Occurrence counts of the two SSL inception modes, termed divert mode and branch mode, are included in Fig. 1b, according to the SSL stroke order. Overall, in 6 of 40 cases, the SSL starts when a dart leader propagates in but diverts from a prior RS channel. More commonly, i.e., in $85 \%$ (34) of distinguishable cases, the SSL propagates from the end of a formerly unsuccessful branch into which the dart leader traveled. Another conceivable SSL inception mode - when an entirely new stepped leader develops from the initiation location of the flash and is not preceded by a dart leader-has not been confirmed in our data. The subset of 40 strokes in which we identify the SSL inception mode occurs in 30 separate flashes.

The average and range of values of preceding interstroke interval (ISI) for the SSL strokes according to inception mode are listed in Table 2. (This table also gives separate values for three sub-types identified within the branch mode; the types are described in Sect. 4.2.) The average ISI for the 88 subsequent strokes that involve a stepped leader is $93.95 \mathrm{~ms}$ with sample standard deviation of $84.11 \mathrm{~ms}$. This average value is long relative to the typical interstroke interval of 60 ms stated by Rakov and Uman (2003) for negative CG flashes. It is also long compared to the distribution in Rakov and Uman (1990) for 516 interstroke intervals (132 flashes), in which $48-64 \mathrm{~ms}$ is most common, $26 \%$ exceed 
Table 2 Preceding interstroke interval (ISI) for subsequent stepped leader strokes

\begin{tabular}{lrlll}
\hline Inception mode & Count & \multicolumn{2}{l}{ Relevant ISI ${ }^{\mathrm{a}}(\mathrm{ms})$} & Maximum \\
\cline { 3 - 5 } & & Minimum & Average & 205.58 \\
\hline Divert & 6 & 39.56 & 129.80 & 205.58 \\
Visible divert & 4 & 117.88 & 164.21 & 309.64 \\
Branch & 34 & 3.98 & 81.06 & 309.64 \\
Visible branch & 22 & 25.16 & 78.95 & 309.64 \\
Early leader (EL) type & 13 & 25.36 & 85.25 & 309.64 \\
Visible EL type & 8 & 25.36 & 96.87 & 165.86 \\
Competing leader (CL) type & 13 & 3.98 & 77.20 & 115.0 \\
Visible CL type & 7 & 25.16 & 62.50 & 119.52 \\
Branched Dart Leader (BDL) type & 8 & 30.82 & 80.62 & 118.84 \\
Visible BDL type & 7 & 30.82 & 75.06 & \\
SSL with mode identified & 40 & & 88.39 & 716.97 \\
Transition visible & 26 & & 92.11 & \\
Mode not identified & 48 & 6.00 & $98.58^{\mathrm{b}}$ & $93.95 \mathrm{~ms}(\mathrm{sample} \mathrm{std}$ \\
All with SSL & 88 & & dev = 84.11) \\
\end{tabular}

${ }^{a}$ In three cases, the relevant ISI has an intervening stroke (relevant ISI is RS3-RS1 time or RS4-RS2 time or RS5-RS3 time). Intervals to the preceding stroke (vs relevant stroke) in these cases are 62.68 (vs 117.88), 63.72 (vs 155.20), and 79.02 (vs 115.00) ms. There are other cases in which the prior RS may not be the most relevant, due to various interstroke activity

${ }^{b}$ Average includes outliers. Maximum value is an outlier; the next longest ISI values are 299.64, 221.84, and $205.58 \mathrm{~ms}$. Minimum is an outlier; the second shortest is $32.34 \mathrm{~ms}$ which occurs in the same flash
$96 \mathrm{~ms}$, and about 8\% exceed $192 \mathrm{~ms}$. For comparison, in the full set of 488 subsequent RSs used for this study (including these 88 ), the average ISI is $87.1 \mathrm{~ms}$ with standard deviation of $81.58 \mathrm{~ms}$ (which is not very different from those for the subset of $88 \mathrm{SSL}$ strokes), the median value is $65 \mathrm{~ms}$, and $30-40 \mathrm{~ms}$ is most common (Fig. 1c). In these 488 subsequent strokes, $30 \%$ (145) have ISI $>96 \mathrm{~ms}$ and $7 \%$ (35) have ISI $>192 \mathrm{~ms}$, quite similar to the values in Rakov and Uman (1990).

\section{Examples of SSL inception modes}

\subsection{Divert mode}

The previously recognized mode of SSL inception (Rakov and Uman 2003) occurs when a dart leader diverts from a prior return stroke channel, then the leader continues to advance as a stepped leader to ground. These subsequent strokes begin in the typical manner as a dart leader propagating toward ground along a prior successful RS channel. At some point part way to ground, the dart leader stops advancing. After a pause of 80-160 $\mu$ s in visible downward propagation, the leader begins advancing as a stepped leader along a new path. In the set of 40 cases in which the SSL inception is either visible or can be deduced from the channel overlap and leader type at various points, we find six in which the SSL diverts from a dart leader, as it travels along a prior RS channel. In these so-called 'divert' cases, the entire portion of the subsequent RS channel above the diversion point is shared with an earlier RS.

Some basic characteristics of the four divert mode cases in which the leaders are clearly visible in the video data are given in Table 3. Note that these four cases have four different stroke orders, indicating no tendency in that regard. In addition, two of the four cases have an intervening stroke between the SSL and the prior RS channel from which it diverts. The relevant interstroke interval, or the time from the prior RS in the relevant channel to the RS that follows the SSL, is long (>117 ms) in each case. The duration of the SSL propagation varies from 1.07 to $12.56 \mathrm{~ms}$. The altitude of the diversion point or location, where the SSL steps away from the prior channel correspondingly varies widely, from 350 to $2090 \mathrm{~m}$ above ground.

One example of a divert mode SSL inception is shown in Fig. 2. In this case from 1 August 2011 (first column in Table 3), the second stroke involves an SSL for the lowest $430 \mathrm{~m}$. Beginning $201.86 \mathrm{~ms}$ after the first RS (RS1), the video data indicate a DL travels down the RS1 channel for $2.0 \mathrm{~ms}$. The visible DL advance then stops at a point along the RS1 channel. We note that this point had been the branch-off point for multiple branches during the first stepped leader, but none of those branches are used during the second stroke, nor is the main RS1 path used below this point. About $140 \mu$ s ( 7 frames) after the DL stopped, the beginning of the SSL propagation is visible as stepped leader 
Table 3 Characteristics of four visible 'divert mode' subsequent stepped leader inceptions

\begin{tabular}{lllll}
\hline Flash date, time & $8 / 01 / 2011$ & $8 / 14 / 2011$ & $8 / 14 / 2011$ & $8 / 12 / 2011$ \\
& $1931: 04$ UT & $2133: 56$ UT & $2129: 18$ UT & 2041:39 UT \\
\hline SSL stroke & 2 nd & 5 th & 3 rd & 4 th \\
Diverts from channel & RS1 & RS3 & RS1 & RS1, 2, 3 \\
Prior interstroke interval (ms) & 205.58 & 63.72 & 62.68 & 178.17 \\
Relevant interstroke interval (ms) & 205.58 & 155.2 & 117.88 & 178.17 \\
Prior RS in channel to DL stop (ms) & 203.86 & 149.78 & 105.16 & 177 \\
Duration of pause (ms) & 0.14 & 0.12 & 0.16 & 0.1 \\
SSL start to RS (ms) & 1.58 & 5.28 & 12.56 & 1.07 \\
Altitude of diversion (km) & 0.43 & 1.53 & 2.09 & 0.35 \\
Distance, camera to flash (km) & 12.2 & 12 & 7.2 & 28.1 \\
\hline
\end{tabular}
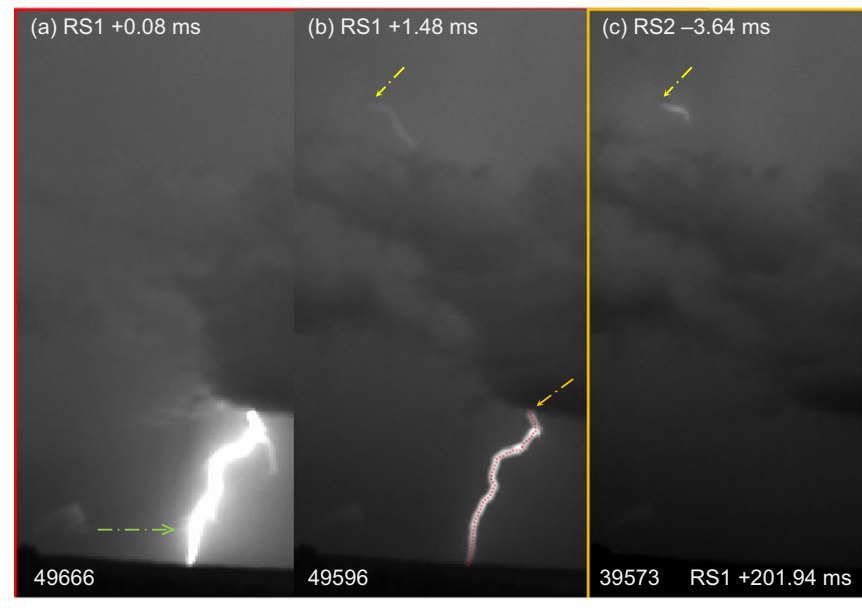

(g) RS2 $-1.72 \mathrm{~ms}$

(h) RS2 $-1.38 \mathrm{~ms}$

(i) RS2 $-0.08 \mathrm{~ms}$
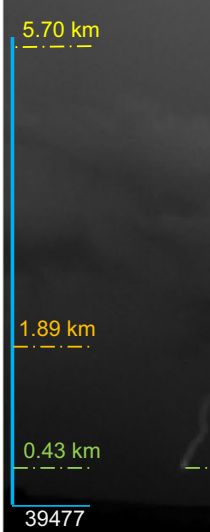

Fig. 2 Example of divert mode of SSL inception. Flash occurred 1 August 2011, 1931:04 UT, at $12.2 \mathrm{~km}$ range (to RS1). Sub-cloud channel location of RS1 is traced with red curve in $\mathbf{b}$ and $\mathbf{l}$. Frame numbers (descending integers) are given at lower left of each; images are not sequential. Each exposure is $19.6 \mu \mathrm{s}$. Times relative to each $\mathrm{RS}$ are listed. Interstroke interval is $205.58 \mathrm{~ms}$. Altitudes above ground level are indicated in $\mathbf{g}$. Frame top altitude is $6.50 \mathrm{~km}$; resolution is $30.5 \mathrm{~m} /$ pixel. Frames in $\mathbf{a}$ and $\mathbf{b}$ show RS1, soon after its occurrence, with some lower branches lit, and $1.4 \mathrm{~ms}$ later when the RS1 luminosity is visible above the obscuring cloud, up to $5.7 \mathrm{~km}$ altitude. In c, $201.94 \mathrm{~ms}$ after RS1, a dart leader becomes visible along the same upper path. Over the next $1.88 \mathrm{~ms}$, this DL travels down through the cloud (d), out the cloud base (e, f), and stops advancing near $0.43 \mathrm{~km}$ altitude (g) on the RS1 channel. After frame $\mathbf{g}$, the leader steps to ground along a new path for $1.72 \mathrm{~ms}(\mathbf{h}-\mathbf{j})$. The highest branch lit during RS2, shown in $\mathbf{k}$, joins the channel at $0.43 \mathrm{~km}$ altitude. The uppermost visible portion of the channel illuminates $0.20 \mathrm{~ms}$ after RS2. In this flash, the visible portions of the channel overlap above $0.43 \mathrm{~km}$. Image-projected distance between the strike points is $91 \mathrm{~m}$ ( 3 pixels) 
steps advance away from the prior branch point. This is the diversion point in this case. This SSL propagates to ground for $1.58 \mathrm{~ms}$, with many branches as is usual for negative SL advance, and is followed by RS2. The entire ISI between RS1 and RS2 is $205.58 \mathrm{~ms}$, much longer than the typical value of $60 \mathrm{~ms}$ (Rakov and Uman 2003). As shown in Fig. 2, the visible portion of RS2 overlaps with RS1 above the diversion point, and the image separation between ground connections is just $91 \mathrm{~m}$.

A second example of a divert mode SSL stroke (second column, Table 3) is described later (Sect. 5), in the context of a flash with multiple SSL strokes. Stolzenburg et al. (2013b) have described another example of this mode; see their Figs. 6a and 7a-h, and related text. In that case (third column, Table 3 herein), a dart leader began nearly $49 \mathrm{~ms}$ after RS2 but traveled relatively slowly along the RS1 channel, for about $1 \mathrm{~ms}$, to an inverted-Y branch point (the diversion point) at $2.09 \mathrm{~km}$ altitude. About $160 \mu \mathrm{s}$ after the visible DL advance stopped, the SSL advance began from the diversion point and continued to ground for $12.56 \mathrm{~ms}$. The E-change data for the time of the switch from DL to SSL (Stolzenburg et al. 2013b) clearly show a smaller and quieter pulse character for the SSL portion. The relevant ISI in that case, between RS1 and RS3, was $117.88 \mathrm{~ms}$. The fourth visible example of this type (last column, Table 3 ) is unique in that the channel from which the SSL diverts had been used in three prior strokes. Like the other cases, however, the relevant ISI was very long, $178.17 \mathrm{~ms}$. The DL in this case (not shown) traveled along the prior channel to $350 \mathrm{~m}$ above ground, then stopped. A dim SSL began visibly advancing from that diversion point $100 \mu \mathrm{s}$ ( 5 frames) later, and it propagated to ground over the next $1.06 \mathrm{~ms}$. Notably, three other long DLs also traveled part of this same prior channel path after RS3 and before RS4, but did not reach ground or switch to stepping; hence, they failed to result in return strokes.

\subsection{Branch mode}

The second mode of SSL inception we describe occurs when a dart leader reaches the end of a prior unsuccessful branch and then continues as a stepped leader to ground. During their propagation before becoming stepped leaders, these dart leaders travel along an earlier stepped leader branch or a branch of the initial leader of the flash. Unlike in the divert mode, the lowest portions of these dart leader paths have not carried a return stroke current. In this so-called 'branch' mode, there is sometimes no visible portion of the subsequent RS channel that is shared with a prior RS channel. In other cases, a portion of visible channel is shared. As shown in Table 2, the interstroke interval preceding the 22 visible branch-mode cases averages $78.95 \mathrm{~ms}$, which is significantly shorter than ( half) the ISI average for the 4 visible divert mode cases.

We have categorized the visible branch-mode SSL inceptions into three types: early leader type, competing leader type, and branched dart leader (BDL) type. Examples of each type are shown in the subsections below. As will be shown in the examples and as is suggested by the names we give to the types, the categorization is based on the time during the flash when the branch developed or the form of the branch, according to the visible features in each case. The important differences among these types lie in the fact that some of the branches are less used or have not been visible for a long time (e.g., used only once or only in the initial breakdown (IB) stage of the flash) prior to being traversed by the DL that switches to a successful SSL. The ISI values for the three types are given separately in Table 2 and are discussed below. Although these types provide a useful way to group and describe the many variations that occur, the leader propagation is basically the same across all cases of this branch mode: a dart leader follows a prior branch that ended above ground, and then leader steps from that end to ground. The subsequent leader propagation type is essentially a dart-then-stepped leader. (A variant of this sequence sometimes occurs when the SSL meets a prior RS channel and then darts along this channel to ground, thereby making the leader type a dart-then-stepped-to-dart leader; stepped-to-dart leaders have been described in Stolzenburg et al. 2013b.)

\subsubsection{Branch mode-early leader type}

As the name suggests, in this type of SSL inception, the dart leader travels to the end of an upper level branch that developed as an initial leader (i.e., the leader during the IB stage of the flash, see Stolzenburg et al. 2013c) or very early stepped leader, near the beginning time of the flash. In most cases, the initial leader branch is only visible near the initiation and then not again until it is traversed by the dart leader in the SSL stroke, while in a few cases, the short branch is illuminated during or just after a prior return stroke. In general, SSL strokes of this type have the longest proportion of stepped leader and least amount of shared channel. The subsequent stroke is entirely new channel compared to prior RSs, or there may be some short overlap at the extreme top of the flash. As shown in Table 2, these tend to have long ISI values (average $96.87 \mathrm{~ms}$ for 8 visible cases) compared to the other branch-mode types.

4.2.1.1 Example 1 of branch mode, early leader type A good example of the branch mode-early leader type of SSL inception is shown in Fig. 3. This flash occurred on 26 July 2011 at 1909:01 UT and had five RSs. The successful SSL preceded its fourth RS (RS4), and the RS4 


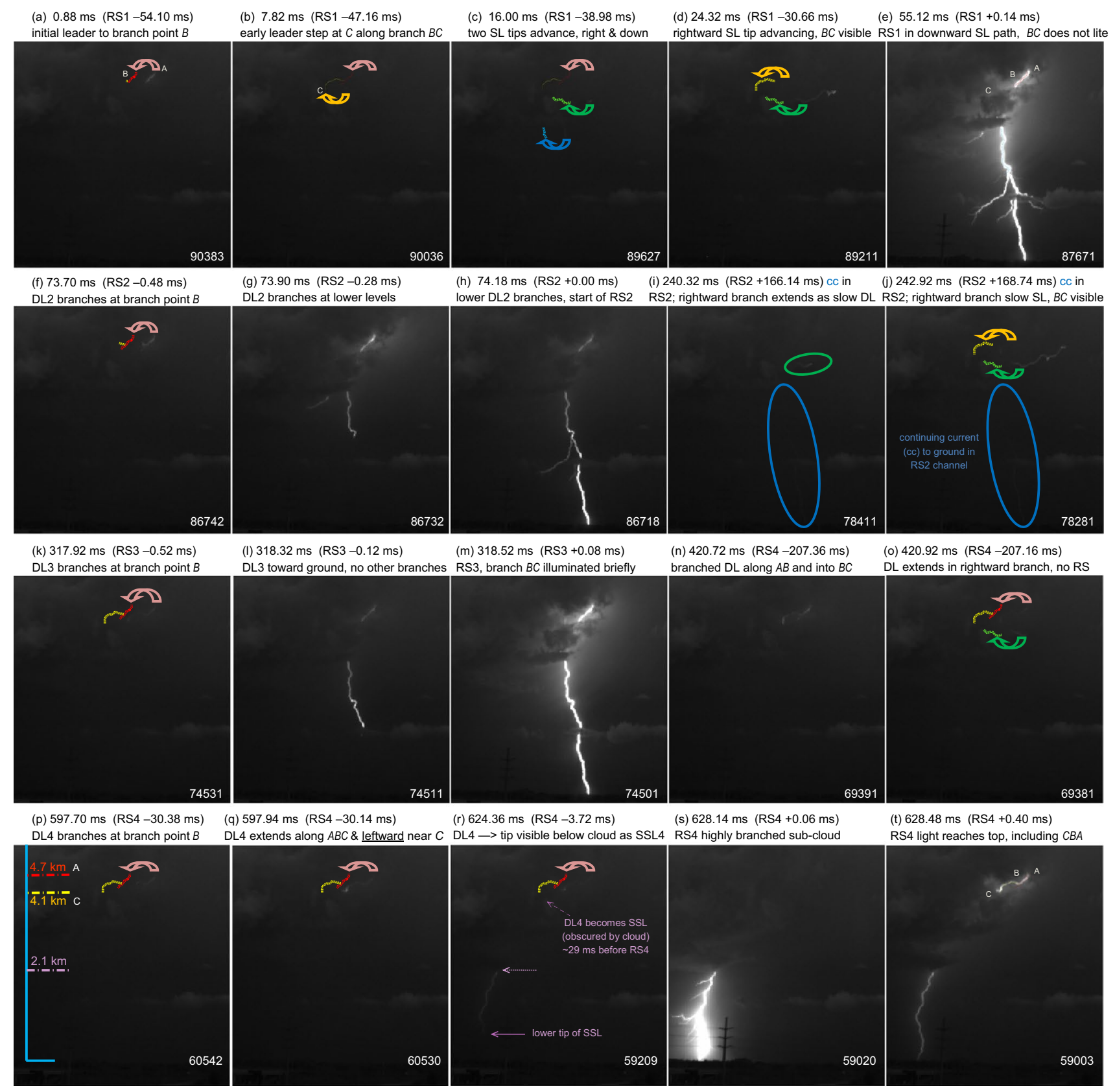

Fig. 3 Example of branch mode-early leader type of SSL inception. Flash on 26 July 2011, 1909:01 UT, at $9.6 \mathrm{~km}$ range to first IB pulse. Times are relative to first luminosity burst (with first IB pulse) which is at point A, 44 frames before frame a. Curved double arrows indicate horizontal translation of the traced portions of the leader paths (colored dashed lines) to the left, for overlay. Frame number for each selected image is given at lower right. Frames in a-e show initial leader and stepped leader (SL) development before and during the first stroke. Frames in $\mathbf{f}-\mathbf{h}$ show branched dart leader (DL) preceding RS2 and $\mathbf{i}, \mathbf{j}$ show extensive leader development during con-

path was also used for RS5. As described in Stolzenburg et al. (2013c), the earliest luminosity in this flash is coincident with the first IB pulse at a spot (labeled A in Fig. 3). This location, at $4.7 \mathrm{~km}$ altitude, is the visible top of all tinuing current ('cc') after RS2. In $\mathbf{k}-\mathbf{m}$, the branched DL to RS3 is shown, followed about $100 \mathrm{~ms}$ later by DL activity shown in frames $\mathbf{n}, \mathbf{o}$ that does not reach ground. Frames in $\mathbf{p}-\mathbf{t}$ show DL starting from the same point $\mathrm{A}$, then following a different branch near the top, then traveling through cloud (obscured) and exiting cloud base as an SSL (purple arrow) and striking ground for RS4. In this flash, the only overlapping channel portion for RS4 and RS1 is at the top (path $B A$ ). Image-projected separation of ground connections is $2.58 \mathrm{~km}$. Frame top altitude, at $24.1 \mathrm{~m} / \mathrm{pixel}$, is $5.25 \mathrm{~km}$

five RSs and also the beginning of the visible portion of all four successful DLs. Several other DLs were unsuccessful, meaning that they did not contact the ground and start a RS. 
The sequence of events associated with the SSL inception in this example is illustrated with the selected video frames, as shown in Fig. 3. After the first IB burst occurs at spot A (frame 90,427, not shown), the initial leader develops downward and splits $0.88 \mathrm{~ms}$ later (frame 90,383, Fig. 3a) near point $B$. The path $\mathrm{AB}$ (i.e., the initial leader portion above this split point) is shared by all five strokes in this flash. Development of the relevant initial leader branch that will be used later for RS4 is partly obscured during this stage; it is visible as a bright spot, the leader tip, several times including at $7.82 \mathrm{~ms}$ (Fig. 3b) at point C. In Fig. 3, the 2-D length of path AB is $475 \mathrm{~m}$, that of path $\mathrm{BC}$ is $650 \mathrm{~m}$, and point $\mathrm{C}$ is at $4.1 \mathrm{~km}$ altitude. During the following downward SL1 development, there is also a developing long horizontal stepped leader branch to the right that is intermittently visible for at least $40 \mathrm{~ms}$ (e.g., Fig. 3c, d). Based on later frames (not shown), this branch is an extension of path $\mathrm{BC}$, although the connection is obscured in Fig. 3c, d. At 3.4 ms before RS1, the downward SL1 branch takes over as the primary luminous activity, and RS1 occurs 55.12 ms after the starting burst. The long horizontal branch (to the right) and the relevant early leader branch (BC) do not illuminate during RS1 (e.g., Fig. 3e).

Interstroke activity is often important in the branch mode of SSL inception. In this example, beginning about $18.64 \mathrm{~ms}$ after RS1, a branched DL travels along path AB. This DL is also visible along branch $\mathrm{BC}$ briefly (e.g., Fig. 3f), then it travels down the RS1 channel to ground in $0.56 \mathrm{~ms}$ (Fig. 3g, h). Branch BC does not illuminate during the brightest time immediately after RS2. The RS1-RS2 interstroke interval is relatively short, $19.20 \mathrm{~ms}$. A very long continuing current follows RS2, with the channel visible to ground in the video data for about $185 \mathrm{~ms}$ (9250 frames). Beginning $164.78 \mathrm{~ms}$ after RS2, during this long continuing current, a slow DLtype leader travels along path $\mathrm{BC}$ and then along the rightward path (e.g., Fig. 3i) for about $3 \mathrm{~ms}$. This leader then extends the rightward path as a slowly advancing SL (e.g., Fig. 3j) for another $34.4 \mathrm{~ms}$ (37.4 ms total visible time). The tip of this long, horizontally extending, slowly advancing leader, is last seen near $3.4 \mathrm{~km}$ altitude and about $2.5 \mathrm{~km}$ (2-D image projected) to the right from point $\mathrm{C}$, then it fades about $202 \mathrm{~ms}$ after RS2.

The third stroke in this flash also follows the RS1 path to ground. At $243.64 \mathrm{~ms}$ after RS2 (and $41.5 \mathrm{~ms}$ after the previous activity ceases), a bright DL begins traveling down the prior path $\mathrm{AB}$. This DL is visible briefly in the branch BC (Fig. 3k), then it travels to ground in $0.62 \mathrm{~ms}$ (Fig. 3l). Unlike in the prior two RSs, however, branch BC is illuminated briefly, as the RS3 luminosity reaches the top of the channel (Fig. 3m). No long continuing current luminosity is visible after RS3; the channel fades away in about $14.1 \mathrm{~ms}$. The RS2-to-RS3 interstroke interval is $244.26 \mathrm{~ms}$.
During the interstroke interval after RS3, there is an optically quiet (dark) period for about $88 \mathrm{~ms}$. This dark period ends when an attempted dart leader becomes visible about $102.1 \mathrm{~ms}$ after RS3; it travels briefly in the AB and $\mathrm{BC}$ paths and extends into the rightward horizontal branch (e.g., Fig. 3n, o). This dim branched DL is not visible after $0.54 \mathrm{~ms}$ of propagation and apparently fails. Another dark period follows for $176.34 \mathrm{~ms}$.

Finally, about $278.98 \mathrm{~ms}$ after RS3, another DL begins and travels along both paths $\mathrm{AB}$ and $\mathrm{BC}$ (e.g., Fig. 3p). Unlike any prior visible activity, this leader extends into a leftward branch from a split near point $\mathrm{C}$, as shown in Fig. 3q. The uppermost leader portion is then intermittently visible through the next $30 \mathrm{~ms}$. Meanwhile, about $20 \mathrm{~ms}$ after the start of this DL, a dim-stepped leader tip becomes increasingly visible advancing downward, far to the left of any visible prior activity in the flash (e.g., Fig. 3r). This SSL connects to a new ground location for RS4 at $309.64 \mathrm{~ms}$ after RS3 and $628.08 \mathrm{~ms}$ after the first IB burst. The RS4 channel is highly branched below cloud base (Fig. 3s), and its luminosity reaches point $A$ at the top of the channel via the CBA path (Fig. 3t). In this example, the SSL begins at about $4 \mathrm{~km}$ altitude and travels to ground in $29.5 \mathrm{~ms}$. The RS4 channel overlaps with that of the prior three strokes only for the top-most $475 \mathrm{~m}$.

As mentioned above, the final stroke of the flash, RS5, follows the entire RS4 channel. The interstroke interval to RS5 is $125.58 \mathrm{~ms}$, and DL5 travels to ground in $1.10 \mathrm{~ms}$. In total, the high-speed video data for this flash yield a duration of about $768.6 \mathrm{~ms}$ (38,430 video frames) from first IB burst to last visible continuing current luminosity in the RS5 channel.

\subsubsection{Example 2 of branch mode, early leader} type Another good example of the branch mode-early leader type of SSL inception is summarized in Fig. 4. This flash occurred on 1 August 2011 at 1935:08 UT and had 12 return strokes. All the strokes followed the same path to ground except RS4 which involved a long SSL and an entirely different path.

In this flash, the earliest visible indication of stepped leader advance in the video data was $17.88 \mathrm{~ms}$ before RS1. This activity occurred near $5.6 \mathrm{~km}$ altitude, started $11.26 \mathrm{~ms}$ after the first IB pulse, and was not along the eventual RS 1 path. About $1.6 \mathrm{~ms}$ later, the stepped leader to RS1 became visible about $340 \mathrm{~m}$ to the right of the previous activity, and it advanced to ground over the next $16.26 \mathrm{~ms}$ (Fig. 4a-d). During RS1 (e.g., Fig. 4e), the earliest leader path did not illuminate near the top of the visible channel. RS1 had a long duration fork connection to ground, visible for $2.10 \mathrm{~ms}$, and a large estimated peak current magnitude of $88.7 \mathrm{kA}$.

Visible branched DLs began $0.68 \mathrm{~ms}$ and $0.22 \mathrm{~ms}$ before RS2 and RS3, respectively. Both strokes used the RS1 

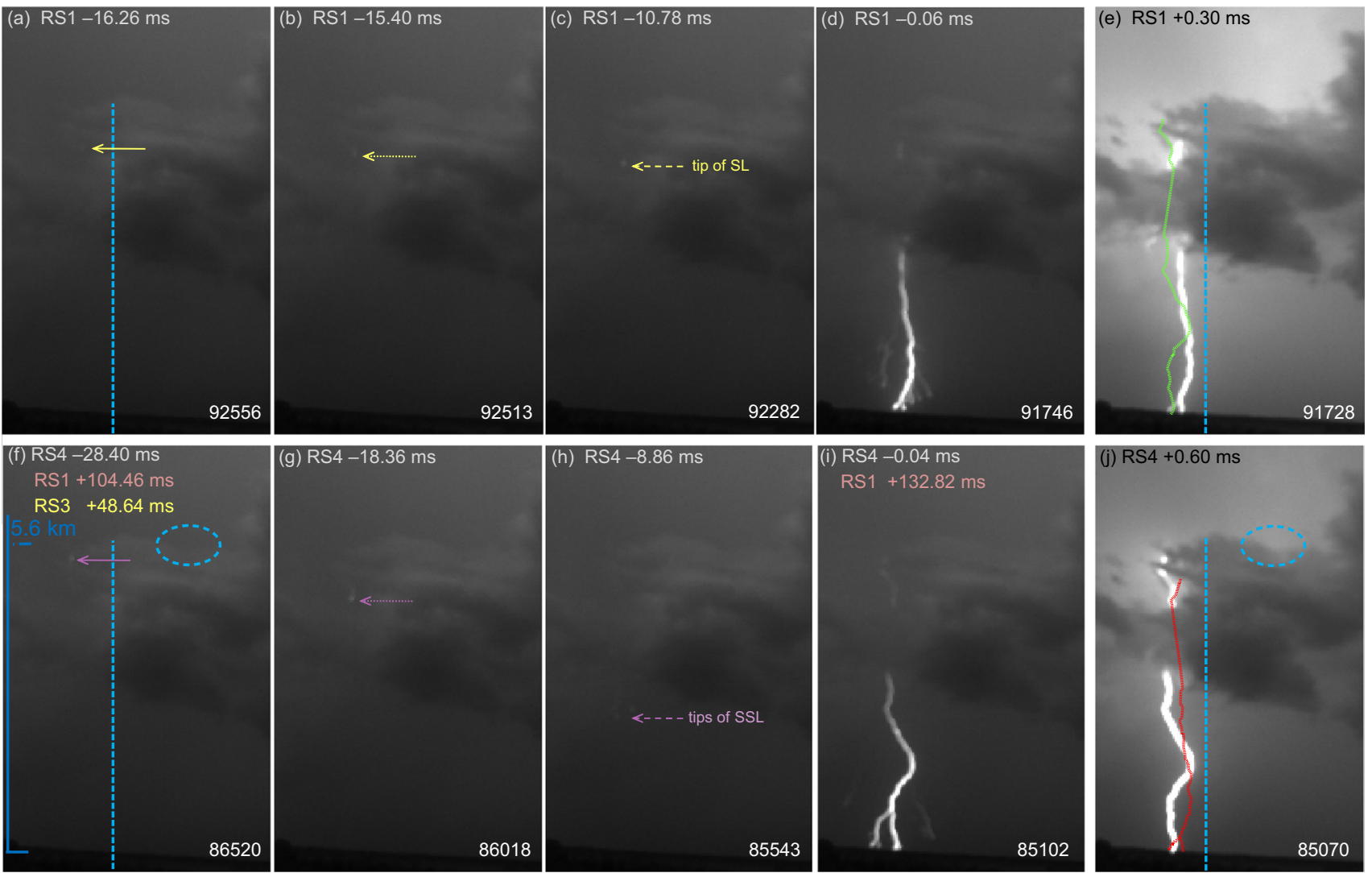

Fig. 4 Example of branch mode-early leader type of SSL inception. Flash on 1 August 2011, 1935:08 UT, at $13.7 \mathrm{~km}$ range to the first RS. Frame number (descending integers) for each selected image is given at lower right; each image exposure is $19.6 \mu \mathrm{s}$. Frame end time relative to RS is listed at top. Blue dashed vertical line is for reference. Frames in a-d show stepped leader development before the first RS; RS1 shown in frame e had a long-lasting forked ground connection. About $104 \mathrm{~ms}$ later and $0.48 \mathrm{~ms}$ prior to frame $\mathbf{f}$ there was a bright burst of luminosity, centered in the region of the blue oval and corresponding to the start of a dart leader along the earliest leader path. By the time of frame $\mathbf{f}$ DL had switched to stepping near the

channel and some of its branches. Beginning $48.16 \mathrm{~ms}$ after RS3, bright luminous activity and a brief dart leader become visible along the earliest leader; this activity switches to obvious stepped leader advance within $0.48 \mathrm{~ms}$, as shown in Fig. 4f. Through the next $28.4 \mathrm{~ms}$, this SSL advances to ground for RS4 (Fig. $4 \mathrm{~g}-\mathrm{j}$ ). From the perspective of the video camera, the RS4 ground location is quite close to the fork connection of RS and just $171 \mathrm{~m}$ from the main RS1 (and all other RS) locations. However, the 2-D locations are $4.5 \mathrm{~km}$ apart, with RS4 about $4.4 \mathrm{~km}$ closer to the camera. The switch from dart leader to SSL is near $5.50 \mathrm{~km}$ altitude in this case. Notably, the earliest leader path in which the brief dart leader traveled had first been seen about $122 \mathrm{~ms}$ earlier, and no visible activity had occurred along the path in the intervening time. There is no visible shared channel in RS4 with RS1-RS3 in this case. The only other visible top visible point. Frames in $\mathbf{f}-\mathbf{i}$ show four frames of the SSL that was visible for $28.68 \mathrm{~ms}$ before RS4. Path of RS1 channel is traced in red overlay on $\mathbf{j}$; RS4 path is traced in green overlay on $\mathbf{e}$. In this flash, there is no visible overlapping channel portion for RS4 with RS1. Image-projected separation of RS ground connections is $171 \mathrm{~m}$ (to longer lasting, main fork of RS1, on right). Top visible altitude of all RSs is about $5.6 \mathrm{~km}$, using spatial resolution of $34.25 \mathrm{~m} /$ pixel. The other 10 subsequent strokes in this flash followed the RS1 channel to ground. An attempted dart leader traveled along the RS4 channel for $0.1 \mathrm{~ms}$ beginning $14.44 \mathrm{~ms}$ after frame $\mathbf{j}$, but failed to reach ground

activity along the RS4 channel was an attempted dart leader that traveled briefly in the upper portion beginning $14.04 \mathrm{~ms}$ after RS4.

Similar to the prior example, this flash has long duration of at least $780 \mathrm{~ms}$ from first IB pulse to the end of the continuing current after the last RS. Intermittent visible activity spreads across $767.32 \mathrm{~ms}$ (38,366 frames) in the video data. Ten dart leaders are visible for most of their $\sim 5600 \mathrm{~m}$ vertical length; their estimated average 1-D speed ranges from 2.41 to $35.0 \mathrm{~m} / \mu \mathrm{s}$, with median value of $9.33 \mathrm{~m} / \mu \mathrm{s}$.

4.2.1.3 Additional examples Another flash with this type of SSL inception is described and shown in Stolzenburg et al. (2013b), as Example 1 therein. In that case, a slow horizontal dart leader switched to stepping near $3.37 \mathrm{~km}$ altitude then traveled downward for $14.64 \mathrm{~ms}$ until it met 
the prior channel to ground for RS2. The E-change data (Stolzenburg et al. 2013b, Fig. 2c) clearly show the relatively large amplitude pulses of the dart leader cease, then small amplitude pulses of the SSL begin. The ISI preceding RS2 in that case was $55.20 \mathrm{~ms}$, shorter than most SSL cases partly because this SSL switched back to a (much faster) DL to ground at $1.57 \mathrm{~km}$. The next stroke in this flash had an SSL inception of the divert mode (mentioned in Sect. 4.1 and listed in Table 3).

Two other visible examples of this common type of SSL inception are worthy of mention to give an impression of the variety among cases, although they are not shown herein. One example flash (8 August, 1620:34 UT) had four return strokes and one UI-type stroke after RS1. Each RS connected to a different ground location, with RS2 using the UI stroke ground location. The SSL to RS4 was of the branch mode-early leader type. After the dart leader began with a characteristically bright burst, the entire leader propagation to RS4 was visible for $28.94 \mathrm{~ms}$. The brief dart leader portion of the fourth stroke traveled along a path that had illuminated as a short branch $198.52 \mathrm{~ms}$ earlier, during (within $0.40 \mathrm{~ms}$ after) RS1, at the extreme top of the flash. This short branch had not been used by any of the prior RS channels. In this SSL case, the entire preceding ISI (from RS3 to RS4) was $87.10 \mathrm{~ms}$. The RS4 ground location was $3.5 \mathrm{~km}$ from the RS1 location. RS4 was followed by at least $155.38 \mathrm{~ms}$ of visible continuing current luminosity. In the same flash, the SSL to RS3 was probably also this type, but was not sufficiently visible for identification.

Another clear example of the branch mode-early leader type of SSL inception occurred in a flash (24 July, 1748:51 UT) with seven RSs that connected to six ground locations. In that flash (not shown herein), the dart leader of the second stroke traveled briefly in a branch of the initial leader. The relevant branch had been visible until the earliest part of the stepped leader stage, but stopped advancing about $7 \mathrm{~ms}$ into the flash when the branch end was at $3.25 \mathrm{~km}$ altitude. Later, after propagating as a dart leader to the end of this early branch, the leader to RS2 advanced as a stepped leader to ground for $9.54 \mathrm{~ms}$. The entire preceding ISI for RS2 was $25.36 \mathrm{~ms}$, which is the shortest ISI value among strokes of this SSL inception type (Table 2). In the flash, the extreme top portion of RS2 is shared with RS1 for about $1070 \mathrm{~m}$ length, then the RS2 channel is different from RS1 below $3.42 \mathrm{~km}$. The other four subsequent stepped leaders in this flash were not captured on high-speed video (due to a power interruption during data offload).

Two additional examples of this type are shown later (Sect. 5), in the context of a flash with multiple SSL strokes of different types.

\subsubsection{Branch mode-competing leader type}

In this second type of SSL inception via the branch mode, the dart leader travels to the end of a prior branch that was not successful, but was visibly stepping near in time before, and in some cases during, the prior RS. In most cases, the branch used during the SSL stroke did not visibly illuminate during the prior stroke, indicating that it may have been electrically cutoff from the main descending leader. The name given to this type comes from the fact that the branch followed by the SSL stroke was earlier visible as a long, competing stepped leader of the sort described in the context of UI-type strokes in Stolzenburg et al. (2014). However, in these cases, there is no UI occurrence soon after the earlier RS. The SSL strokes of this type generally have the longest proportion of dart leader and shortest stepped leader. There may be visible shared channel at the top of the RSs, above the branch split, depending on where along the main trunk the earlier split occurred relative to cloud base. As shown in Table 2, this type tends to have relatively short ISI values (average $62.50 \mathrm{~ms}$ for sevens visible cases) compared to the other branch-mode types and compared to the average ISI value for the entire data set.

4.2.2.1 Example of branch mode-competing leader type A good example of this branch mode-competing leader type of SSL inception is shown in Fig. 5. This flash (26 July, 1907:50 UT) had only two strokes to ground. Beginning about $33.5 \mathrm{~ms}$ prior to the first RS, first one and then two long stepped leaders are visible in the video data. Both these leader ends are visibly stepping to at least $12.3 \mathrm{~ms}$ before RS1 when they reach about $2.0 \mathrm{~km}$ altitude. After this time, only the second of these leaders is dimly visible until it connects to ground for RS1. The other leader path does not illuminate as a visible branch during RS1. About $14.1 \mathrm{~ms}$ after $\mathrm{RS} 1$, an attempted dart leader travels in a third path to just below cloud base before fading and apparently stopping. Then, $5 \mathrm{~ms}$ later, another dart leader travels along the path that was the first visible, long leader prior to RS1. This dart leader switches to stepped leader advance at $1.75 \mathrm{~km}$ altitude, and then, the SSL propagates to ground in $9.9 \mathrm{~ms}$ for RS2. In this case, the interval from when the branch was last seen as a stepped leader until the time when the dart leader becomes an SSL at the same point is $33.0 \mathrm{~ms}$. The ISI from $\mathrm{RS} 1$ to RS2 is $28.90 \mathrm{~ms}$. Although the two channels appear close together in the video data projection, the ground connections are $1.50 \mathrm{~km}$ apart. The visible portion of the RS2 channel is completely different from RS1 except for the topmost portion, near the flash initiation.

Incidentally, the second RS in this flash was followed, $219.16 \mathrm{~ms}$ later, by four intracloud (IC) strokes (at 23.30, 15.52 , and $36.26 \mathrm{~ms}$ intervals) in which a dart leader advanced along a different, mainly horizontal path, then 

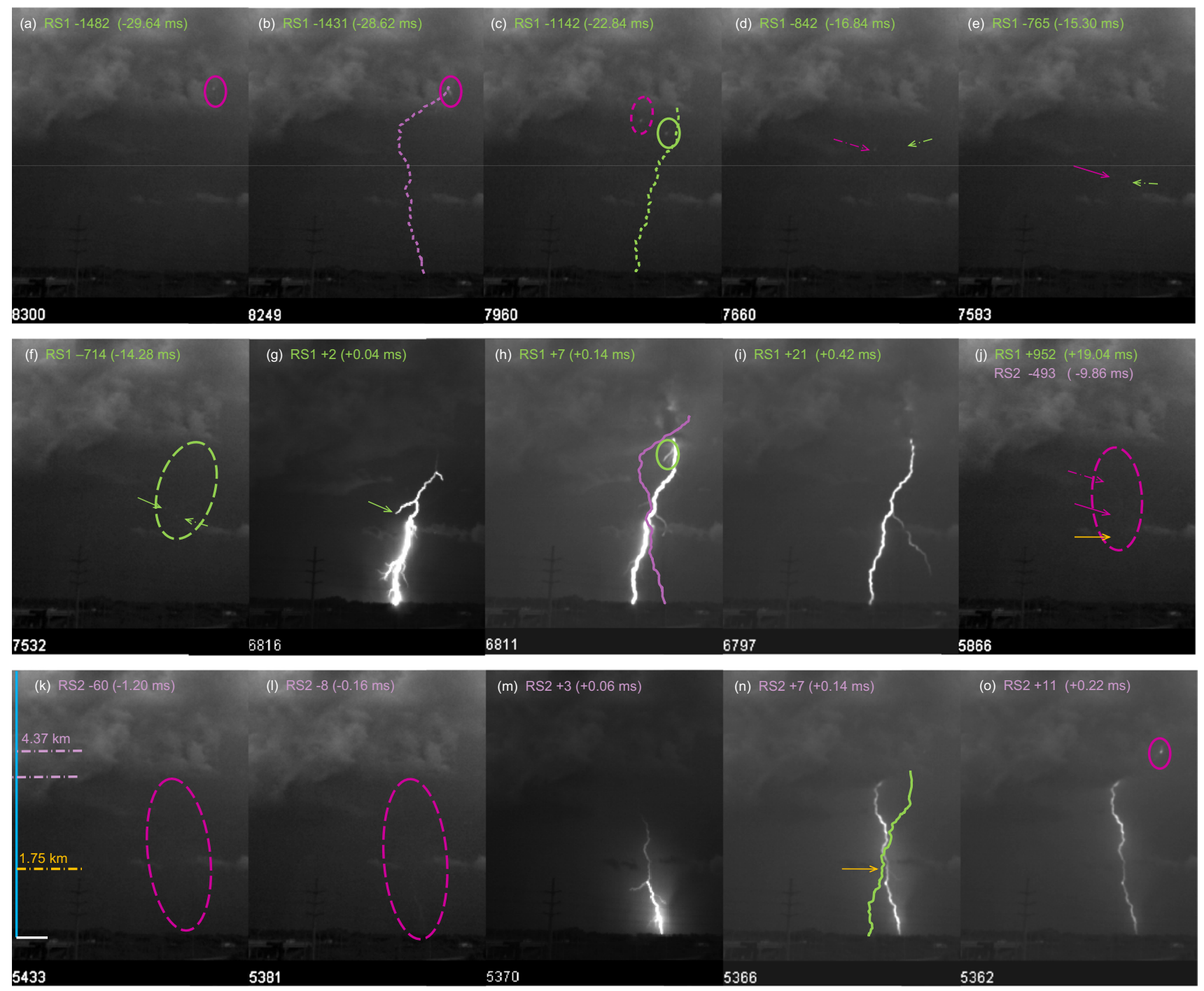

Fig. 5 Example of branch mode-competing leader type of SSL inception. Flash on 26 July 2011, 1907:50 UT, at $11.5 \mathrm{~km}$ range (to RS1). Channel location of RS1 is traced with green curve in $\mathbf{c}$ and $\mathbf{n}$ and that of RS2 is traced with purple curve in $\mathbf{b}$ and $\mathbf{h}$. Frame numbers are given at lower left of each selected image. Frames in $\mathbf{a}-\mathbf{e}$ show the early advance of two stepped leaders from 30 to $15 \mathrm{~ms}$ prior to RS1. After frame e the earliest visible SL tip (purple markers) vanishes. The other SL tip (green arrows in $\mathbf{d}-\mathbf{f}$ continues to ground for RS1, shown in $\mathbf{g - i}$. During RS1, the other leader path does not illuminate.

switched to stepped leader advance at the end, before a suddenly bright luminosity wave traveled back along the path. Repeated IC strokes of this sort involving both dart and stepped leader advance are common in flashes with SSL strokes in our CG data set. Both these stroke types are also indicative of the importance of earlier, remaining, unused leader paths to the activity and overall charge transfer by CG lightning.
About 19 ms after RS1, frame $\mathbf{j}$ shows a dim DL has traveled down the prior unused SL path and becomes a dim SSL at the prior end of the unused branch (near orange arrow). The SSL, dimly visible in $\mathbf{k}$, $\mathbf{l}$, steps to ground in $9.9 \mathrm{~ms}$ for RS2, shown in $\mathbf{m}-\mathbf{o}$. Channel connection of the highest branch lit during RS2 is at $1.29 \mathrm{~km}$ altitude. In this flash, there is no overlapping channel portion nor common branches visible in the two RSs; paths are mostly obscured above $4 \mathrm{~km}$. Ground strike points are $1.50 \mathrm{~km}$ apart; image-projected separation is $0.66 \mathrm{~km}$. Frame top altitude, at $28.75 \mathrm{~m} / \mathrm{pixel}$, is $6.30 \mathrm{~km}$

4.2.2.2 Additional examples Another flash with the branch mode-competing leader type of SSL inception is described in Stolzenburg et al. (2014), in their Fig. 15. In that case, a competing stepped leader branch was visible prior to RS1, and it illuminated as a branch during RS1. The same branch was then visible as part of a branched dart leader (BDL) prior to RS2 and RS3, although it was not the path used to ground in either stroke. Beginning about $115.66 \mathrm{~ms}$ after 
RS3, an unbranched dart leader traveled along this branch (only) for $6.40 \mathrm{~ms}$ before reaching its end; it "then steps to a new ground location in $5.2 \mathrm{~ms}$ " (Stolzenburg et al. 2014) for RS4. The entire ISI in that example was $127.26 \mathrm{~ms}$. In addition, Stolzenburg et al. (2015) (their Figs. 4, 6) have described a similar example of this branch mode-competing leader type of SSL inception. The relevant branch in that case was visible as a mainly horizontal stepped leader before and after the first RS, then partially visible as a dart leader branch before RS2 but not seen during the third stroke. Nearly, 68 ms after RS3, a dart leader in the branch switched to advancing as a stepped leader and traveled to ground in about $11.1 \mathrm{~ms}$. In that case, the preceding ISI was $79.03 \mathrm{~ms}$ and the entire time without visible activity along the horizontal branch prior to the SSL inception was $103.5 \mathrm{~ms}$.

One other flash (not shown) with this type of SSL inception is worthy of mention, because it has two visible examples in the second and third strokes. In that case (26 July, 1937:29 UT), multiple unsuccessful branches were illuminated immediately after RS1. About $91.9 \mathrm{~ms}$ after RS1, a dart leader along one of those branches extended into view and then switched to stepping for $4.08 \mathrm{~ms}$ until reaching ground for RS2. Another $53.5 \mathrm{~ms}$ later, the same process occurred along another of the earlier post-RS1 branches; that dart leader switched to stepping $3.58 \mathrm{~ms}$ before reaching ground for RS3. Overall, the flash seemed 'satisfied' with this third channel, as the remaining six strokes followed the entire visible third channel to ground as dart leader/return stroke sequences.

Beyond our prime example of this competing leader type of SSL inception (Fig. 5), these additional cases indicate that prior branches can remain viable for a long time, of order $100 \mathrm{~ms}$, for possible later use by dart leaders, then successful SSLs and return strokes in the flash. This longevity can apparently exist whether or not a prior return stroke illuminated the branch.

\subsubsection{Branch mode-branched dart leader (BDL) type}

The third type of SSL inception we identify within the branch mode involves a BDL. This type occurs when a stepped leader extends from the end of one of several BDL branches that did not previously reach ground. Although differently termed herein, these are the same variety as cases referred to as BDL type 'B then stepped' in Stolzenburg et al. (2014). Strokes involving this type of SSL inception might or might not have visible channel overlap with a prior stroke, depending on the sequence of events and branches followed by the BDL. As with BDLs in general, there are numerous examples in our video data set of these SSL inceptions occurring but failing to reach ground for a return stroke. In some cases, the dart leader branch becomes active again later in the flash, switches to an SSL again, and then succeeds in reaching ground. It is also the case in this type that multiple SSLs sometimes start nearly simultaneously from multiple BDL ends. These factors make video data practically essential for identifying the inception mode and type.

4.2.3.1 Example of branch mode-BDL type One example of this branch mode-BDL type of SSL inception is shown in Fig. 6. In this flash (12 August, 2040:14 UT), the second stroke involves a surprisingly complicated leader sequence. A brief dart leader branch switches to advancing as a visible stepped leader; the inception type of this upper stepped leader is unknown, because the dart leader branch is not sufficiently visible. After advancing as a stepped leader for about $5.3 \mathrm{~ms}$, the SSL meets the prior channel above the altitude of a former branch point (point B in Fig. 6). At the meeting point (point A in Fig. 6), the leader becomes a bidirectional dart leader. The downward dart leader then travels as a BDL in a prior branch and in the prior RS channel for about $0.24 \mathrm{~ms}$. When the BDL reaches the end of the prior branch, at $1.30 \mathrm{~km}$ altitude, it switches to an SSL that steps to ground, for RS2, in $4.52 \mathrm{~ms}$. The entire ISI is $103.30 \mathrm{~ms}$ in this case. The RS2 channel overlaps with the RS1 channel only in the midlevel portion, between the branch point of the BDL and the meeting point of the stepped leader with the former channel.

4.2.3.2 Additional examples Two other similarly complicated cases of this SSL inception type appear in Stolzenburg et al. (2013b), as Example 3 therein, and in Stolzenburg et al. (2014), as Example 9 therein. In the former case, shown in Fig. 14 of Stolzenburg et al. (2013b), a long stepped leader (of unseen inception mode or type) meets a former leader path used by branches of the first stroke. The stepped-todart leader then traveled in multiple BDL branches to their ends. In this case, multiple branch tips concurrently switch to stepped leader advance; hence, the (multiple) SSL inceptions were of the branch mode-BDL type. The SSL branches were then visible advancing toward ground for the $3.36 \mathrm{~ms}$ until RS2. The ISI was $104.34 \mathrm{~ms}$, and the RS2 channel was used by the two subsequent strokes in the flash.

In the latter case, shown in Fig. 16 of Stolzenburg et al. (2014), a dart leader travels along a branch that was visible $0.28 \mathrm{~ms}$ after the first return stroke. This dart leader becomes a BDL in several of its sub-branches until reaching their ends, near $2.0 \mathrm{~km}$ altitude, then switches to stepping. Thus, the SSL inception is again of the branch mode-BDL type. The SSL reaches ground in $5.74 \mathrm{~ms}$ for RS2, which had full preceding ISI of $77.98 \mathrm{~ms}$. The highly branched SSL of the second stroke is nicely revealed as a BDL in the third stroke of the flash, and the RS2 channel was used by the two subsequent strokes in the flash. 

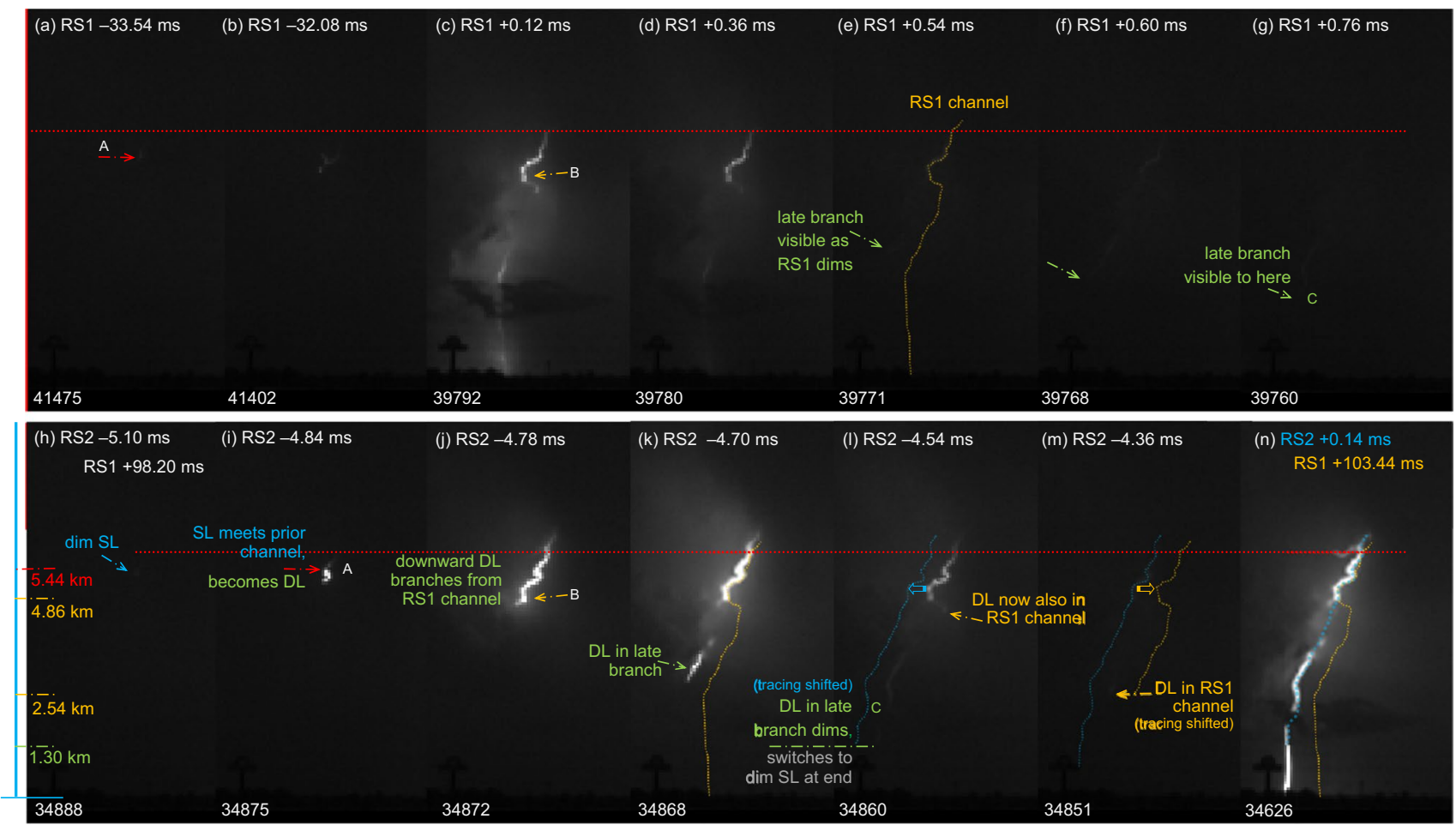

Fig. 6 Example of branch mode-branched dart leader (BDL) type of SSL inception. Flash on 12 August 2011, 2040:14 UT, at $29.0 \mathrm{~km}$ range to RS1. RS1 channel is traced in orange; DL portion of RS2 channel is traced in blue. Frame numbers of selected images are given at bottom of each. Interstroke interval is $103.30 \mathrm{~ms}$ and ground connections are $870 \mathrm{~m}$ apart on the image. Altitudes above ground are given alongside of $\mathbf{h}$. Red horizontal line at $6.09 \mathrm{~km}$ is altitude of first visible luminosity, above point A, starting $2.28 \mathrm{~ms}$ before frame shown in a. Resolution is $72.5 \mathrm{~m} / \mathrm{pixel}$, using $29.0 \mathrm{~km}$ range for entire image. Frames in a-f show leader activity before, channel during, and branch activity soon after RS1, when a late branch illuminates (visible down to point $\mathbf{C}$ ) as the RS1 channel fades. Frame in $\mathbf{h}$ shows a subsequent stepped leader beginning from the end of an unseen dart leader from near the first luminosity spot. The SSL finds the prior path at point $\mathrm{A}$ (frame i) and becomes a bidirectional dart leader. When it reaches point $\mathrm{B}$, the downward dart leader splits first into the late branch (frames $\mathbf{j}, \mathbf{k}$ ), and then, by the time of frame $\mathbf{l}$, the DL is also visible in the prior RS1 channel. When the DL reaches the end of the late branch at frame $\mathbf{l}$, below point $\mathrm{C}$, it becomes a subsequent stepped leader and connects to ground about $4.5 \mathrm{~ms}$ later. Frame in $\mathbf{n}$ shows RS2, with position of RS1 channel indicated. In this flash, the visible portions of the two RS channels overlap only between point $\mathrm{B}$ and point $\mathrm{A}$
In both these cases from the recent literature, the switch from BDL to SSL advance is obvious in the corresponding E-change data as a characteristic sudden decrease in amplitude and cease of erratic behavior of the leader pulses (Stolzenburg et al. 2013b, 2014). A similar change in pulse character in E-change data (not shown) was observed in the example of Fig. 6, and such a change is typical of the switch from dart leader to stepped leader of any type in our data. In both these cases, there was no dart leader branch visible traveling along the prior successful leader of the first stroke, and in both cases, the second RS channel had no visible overlap with the prior RS channel. This aspect is unlike the example in Fig. 6, where there is a short piece of visible shared channel. Together, these three examples help illustrate some of the variety observed within this type of SSL inception.

\section{Flash with multiple SSL inception types}

Among the 18 flashes in the video data set that have multiple SSL strokes, here we present one example that has four strokes involving SSLs. Among these four SSL inceptions, one is a divert mode, two are branch mode-early leader type, and one is branch mode-BDL type. This flash, which occurred at 2133:56 UT on 14 August, was used by Karunarathne et al. (2013) to compare PBFA locations to video and other data in validating their time-of-arrival technique. In the present study, the same data support the conjecture that the pre-flash charge structure (alone) does not govern the SSL inception mode or type.

An overview of the video, E-change, and source location data is shown in Fig. 7, which is partly adapted from 


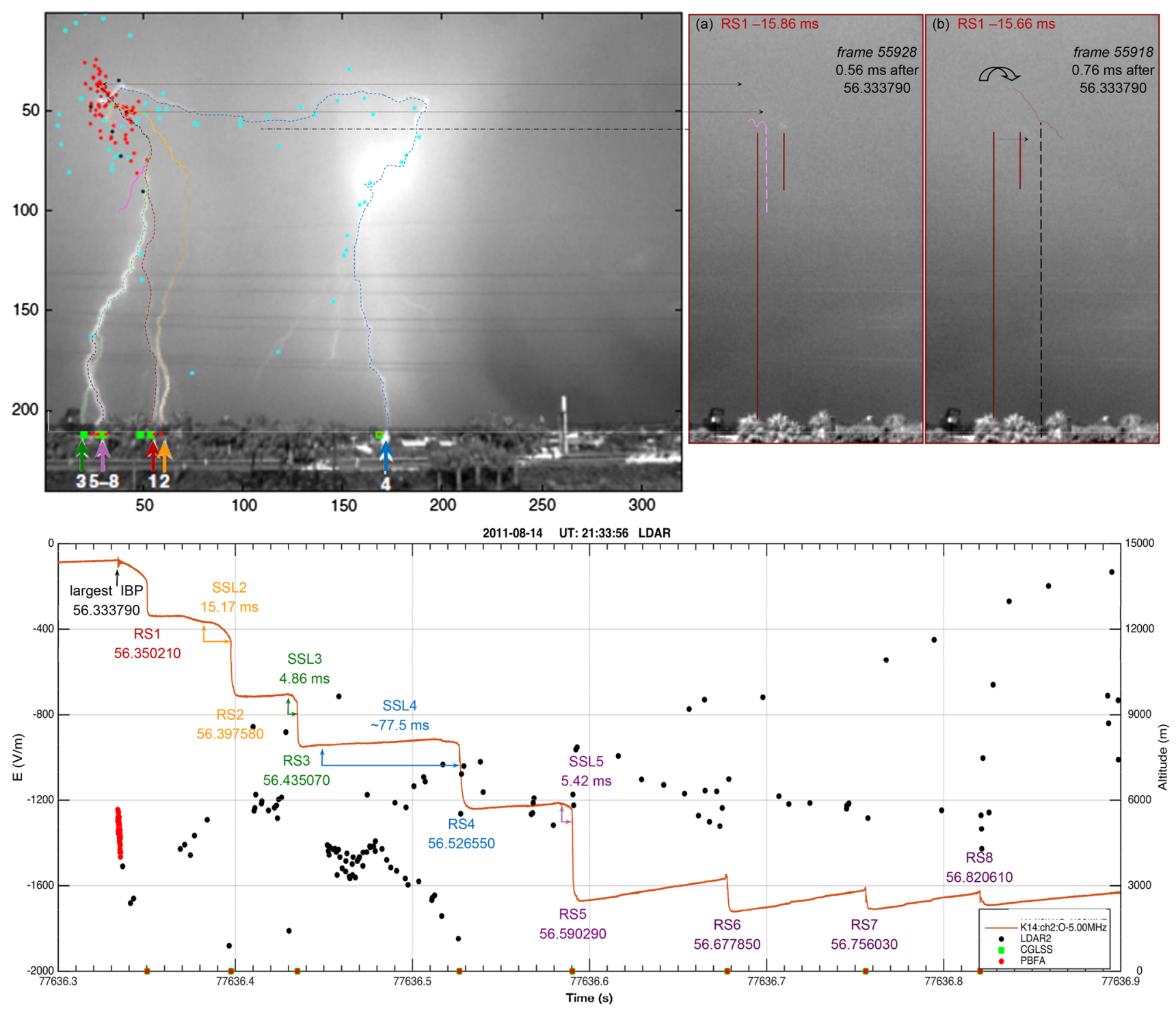

Fig. 7 Overview of flash at 2133:56 UT (77636 s past 00 UT), 14 August 2011. Top left panel is integrated image (adapted from Karunarathne et al. [2014]) combining 8 separate individual video frames of the 8 RSs. Numbered arrows indicate RS ground locations in video data. Colored dots (red from E-change data for first $5 \mathrm{~ms}$ and for RS locations, black from VHF data in first $5 \mathrm{~ms}$, cyan from VHF data of stepped leaders) and lime-green squares (CGLSS data) are source locations derived from three sensor arrays, projected onto the image plane at $12 \mathrm{~km}$ range. Scale is in pixels; image resolution is $\sim 30 \mathrm{~m}$ per pixel. The first IB pulses occurred near $5.2 \mathrm{~km}$ altitude; frame top is $6.24 \mathrm{~km}$ altitude. Full image width is $9.6 \mathrm{~km}$. Dashed curves are tracings of the full RS channels, based on video data. Overlap of upper channel portions with E-change data source locations during the first $5 \mathrm{~ms}$ supports RS2 and RS4 developing from

Fig. 11 in Karunarathne et al. (2013). The overlap of some uppermost channel portions in the images with the PBFA source locations during the first $5 \mathrm{~ms}$ (red dots) fits with detailed analyses (shown below) that RS2 (orange) and RS4 (dark blue) each involved SSLs of the branch
SSLs of the branch mode-initial leader type of inception, with almost no shared channel with any other RSs. SSL to RS3 is a branch modeBDL-type inception, with the upper portion of channel shared by RS1. SSL to RS5 starts via the divert mode, diverting from the RS3 channel at $1.50 \mathrm{~km}$ above ground. RS6, RS7, and RS8 are preceded by dart leaders, only, and follow the entire RS5 path to ground. Individual cropped frames $\mathbf{a}, \mathbf{b}$ at top left show earliest visible activity, as shown in Fig. 8a, b. Lower panel is a time series showing $600 \mathrm{~ms}$ of E-change data (red curve, left axis) and source altitudes (right axis) from the three sensor arrays. Times (min. seconds) of the largest initial breakdown pulse and each return stroke are listed. Durations of the four subsequent stepped leaders are given, and their start times are indicated with the short upward arrows

mode-early leader type of inception. These two strokes had long SSL durations and almost no shared channel with any other RS. The SSL to RS3 was a branch mode-BDLtype inception, with the upper portion of channel shared by RS1. The SSL to RS5 started via the divert mode, 
diverting from the RS3 channel at $1.50 \mathrm{~km}$ above ground. The final three return strokes (RS6, RS7, and RS8) were preceded by dart leaders, only, and followed the entire RS5 path to ground.

Select video images for the first and second strokes of this flash are presented in Fig. 8. The top segment of the RS1 path (faint but visible, traced in Fig. 8b, d), developed and branched within the first $3 \mathrm{~ms}$ of the flash, during the IB stage. One initial leader branch developed into the stepped leader to RS1. Later, $17.48 \mathrm{~ms}$ after RS1, another of these early branches was traversed briefly by an attempted dart leader (not shown). The E-change data in Fig. 9a support the video analysis that this early attempted dart leader switched to stepping and then advanced (for several $\mathrm{ms}$ ), but did not reach ground. This sequence was repeated 14.26 ms later, as shown in Fig. 9a (inset). However, in this instance, the briefly visible dart leader switched to an SSL that did advance to ground in $15.17 \mathrm{~ms}$ for RS2 (e.g., Fig. 8h-j). The comparison between the RS1 and RS2 channels (Fig. 8) indicates that only a short piece of the channel is shared (a 'seagull' shape, traced in pink) at the extreme top. The full interval between RS1 and RS2 is $47.37 \mathrm{~ms}$, and the ground locations are about $500 \mathrm{~m}$ apart.

The third RS in this flash was preceded by an SSL of the branch mode-BDL type. Key video data are shown in Fig. 10, and the corresponding E-change and LDAR2 data for the stroke are shown in Fig. 9b. In this case, the entire sequence of events is complicated by unsuccessful interstroke activity that provides a portion of the eventual RS3 channel. This sequence is depicted in Fig. 10a-c, in which an unsuccessful 'attempted' branched dart leader travels along some upper RS1 branches, then down to an end (approximately at the level indicated by the yellow horizontal guide). This leader advance apparently pauses for $0.26 \mathrm{~ms}$, then advances via stepping for $0.50 \mathrm{~ms}$ before it vanishes. The E-change data in Fig. 9b, including the coincident period of relatively large amplitude pulses during the BDL advance, support this interpretation. The frames in Fig. 10d-g show visible leader activity re-starts about $9.2 \mathrm{~ms}$ later, with another branched dart leader traveling in several upper RS1 branches, including the path of the earlier attempted BDL, until it reaches that prior end after $0.42 \mathrm{~ms}$. The dart leader then switches to stepping (at green horizontal guide
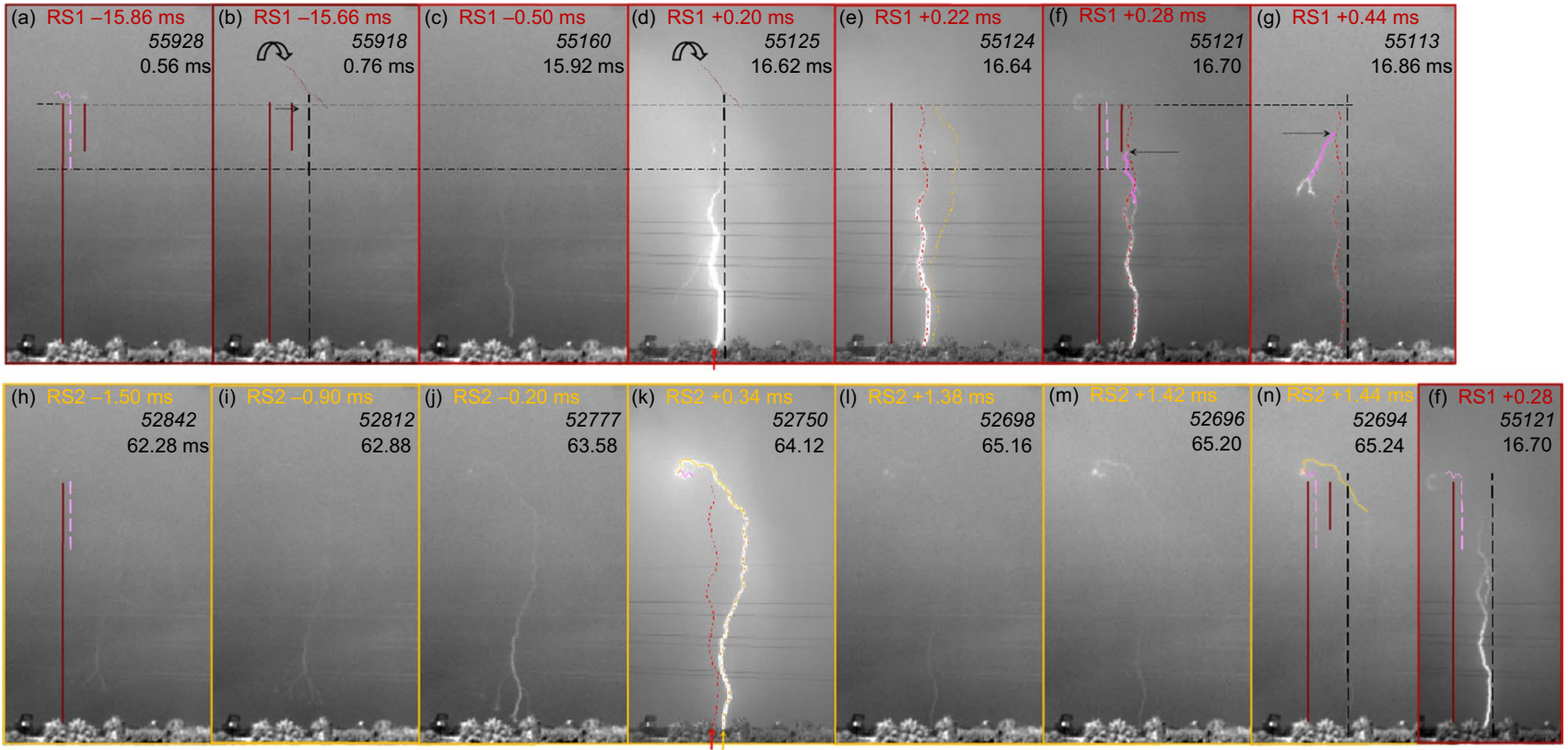

Fig. 8 Example of branch mode-initial leader type of SSL inception, second stroke of flash on 14 August 2011, at 2133:56 UT. Times at top are relative to the first frame of each RS. Frame number is shown in italics, with time (in ms) after the largest IB pulse given (black text). Frame interval of data is $20 \mu \mathrm{s}$; exposure is $19.6 \mu \mathrm{s}$. (Largest IB pulse time is $333.79 \mathrm{~ms}$ after 2133:56.) Vertical and horizontal lines are guides, placed for inter-frame reference. Upward arrows at ground indicate RS connection locations, color-coded (RS1 is red, RS2 is orange). RS1 path is traced with red curve; RS2 path is traced with orange curve. Faint streaks across all images are utility lines in the foreground. Frames in $\mathbf{a}-\mathbf{g}$ show activity before, during, and after
RS1. Uppermost portion of RS1 path traced in red dotted curve is the initial leader that develops and branches during IB stage. (Tracings in $\mathbf{b}$ and $\mathbf{d}$ are translated to right for display, as indicated by double arrow.) Frames in $\mathbf{h}-\mathbf{n}$ are select frames for $1.50 \mathrm{~ms}$ before and after RS2. Dart leader became visible (time $48.52 \mathrm{~ms}$ ) near the top of the pink dashed guide, $13.77 \mathrm{~ms}$ before frame shown in $\mathbf{h}$ and changed to a stepped leader after $0.10 \mathrm{~ms}$. Most of the SSL propagation is too dim to display. Comparison to RS1 channel (frame $\mathbf{f}$ is repeated, far right in lower row) indicates only a very short piece of the channel is shared by RS2 ('seagull' shape, traced in pink) in one initial leader branch 

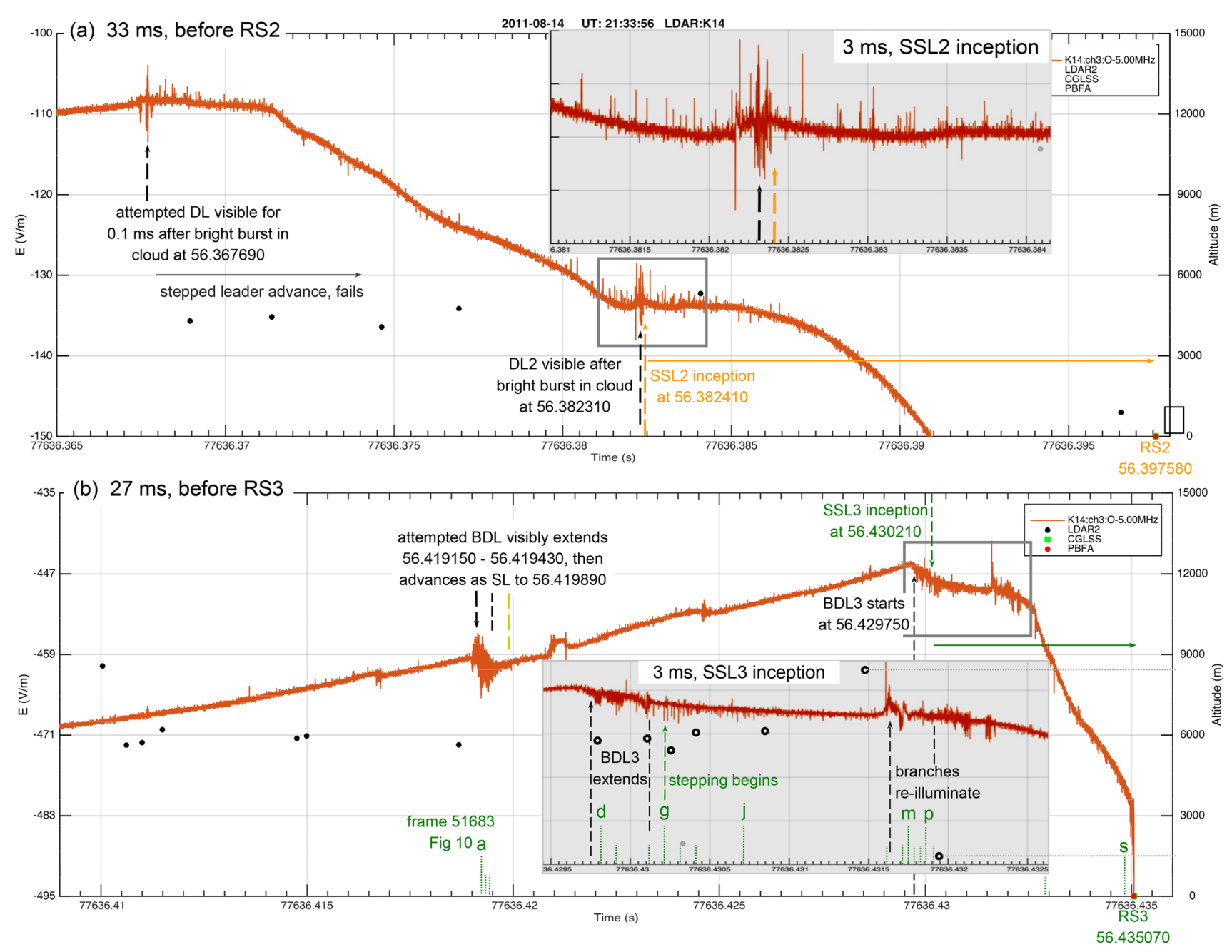

Fig. 9 Time series of E-change data and LDAR2 source altitudes for two subsequent strokes of flash at 2133:56 UT (77636 s past 00 UT), 14 August 2011. a Leader activity prior to RS2, with SSL inception via branch mode-initial leader type (see also Fig. 8). An earlier attempted dart leader fails after briefly advancing; these data indicate the leader switched and advanced as a stepped leader for several $\mathrm{ms}$. The successful dart leader begins $14.6 \mathrm{~ms}$ later and switches to stepping after $0.1 \mathrm{~ms}$. The only LDAR2 source early during the SSL advance is at $5.2 \mathrm{~km}$ altitude. Final $5.5 \mathrm{~ms}$ of SSL and RS E-change data are off scale here (see Fig. 7). Inset plot shows $3 \mathrm{~ms}$ during which the brief dart leader begins then switches from dart to stepped

in Fig. 10) in $0.04 \mathrm{~ms}$ (i.e., two video frames). The inset plot in Fig. 9b also shows this SSL inception as beginning after an interval of $0.04 \mathrm{~ms}$ with no leader pulses. Frames in Fig. 10h-t show the SSL advances to ground through the next $4.80 \mathrm{~ms}$ for RS3. As this SSL proceeds to ground, several dart leader branches (traced in pink, visible also after RS1) illuminate intermittently, for example, in the frames, as shown in Fig. 101-q. These optical events coincide with larger pulse-train events in the E-change data (e.g., Fig. 9b inset) and are not unusual in our data set during stepped leaders. The video frame in Fig. 10u includes a comparison leader, $15.16 \mathrm{~ms}$ before RS2. b Leader activity prior to RS3, with SSL inception via branch mode-BDL type (see also Fig. 10; selected frame times are marked here with dotted vertical lines). An early attempted BDL behaves much like the successful BDL $10.6 \mathrm{~ms}$ later, except the earlier attempt fails about $0.5 \mathrm{~ms}$ after it switches to stepping. Inset plot, including BDL3 advance and SSL inception, shows that there is a very brief pause (about $0.08 \mathrm{~ms}$ ) between evident BDL pulses and first SSL pulses, in agreement with the video data (Fig. 10, frames $\mathbf{g}, \mathbf{h})$. The full field change to RS3 is off scale here. Open circles in $\mathbf{b}$ are LDAR2 points covered by the inset but shown through correctly on the time and altitude axes of the full $27 \mathrm{~ms}$ plot

of the first three RS channels, indicating the location of shared channel at the top (level of vertical red bar and above) in RS3 and RS1. The uppermost portion of the RS1 path is visible in RS3. (In Fig. 10, the tracing of RS1, the red dotted curve, is translated to the right for display, as indicated by double arrow.) There is no visible shared channel with RS2 in RS3. The interval between RS1 and RS3 is $84.84 \mathrm{~ms}$; between RS2 and RS3 is $37.48 \mathrm{~ms}$. (Frames (1f) and (1g) in Fig. 10 are as in (f) and (g) from Fig. 8, for RS1; they are repeated to facilitate comparison of the channels and postRS1 branches.) 

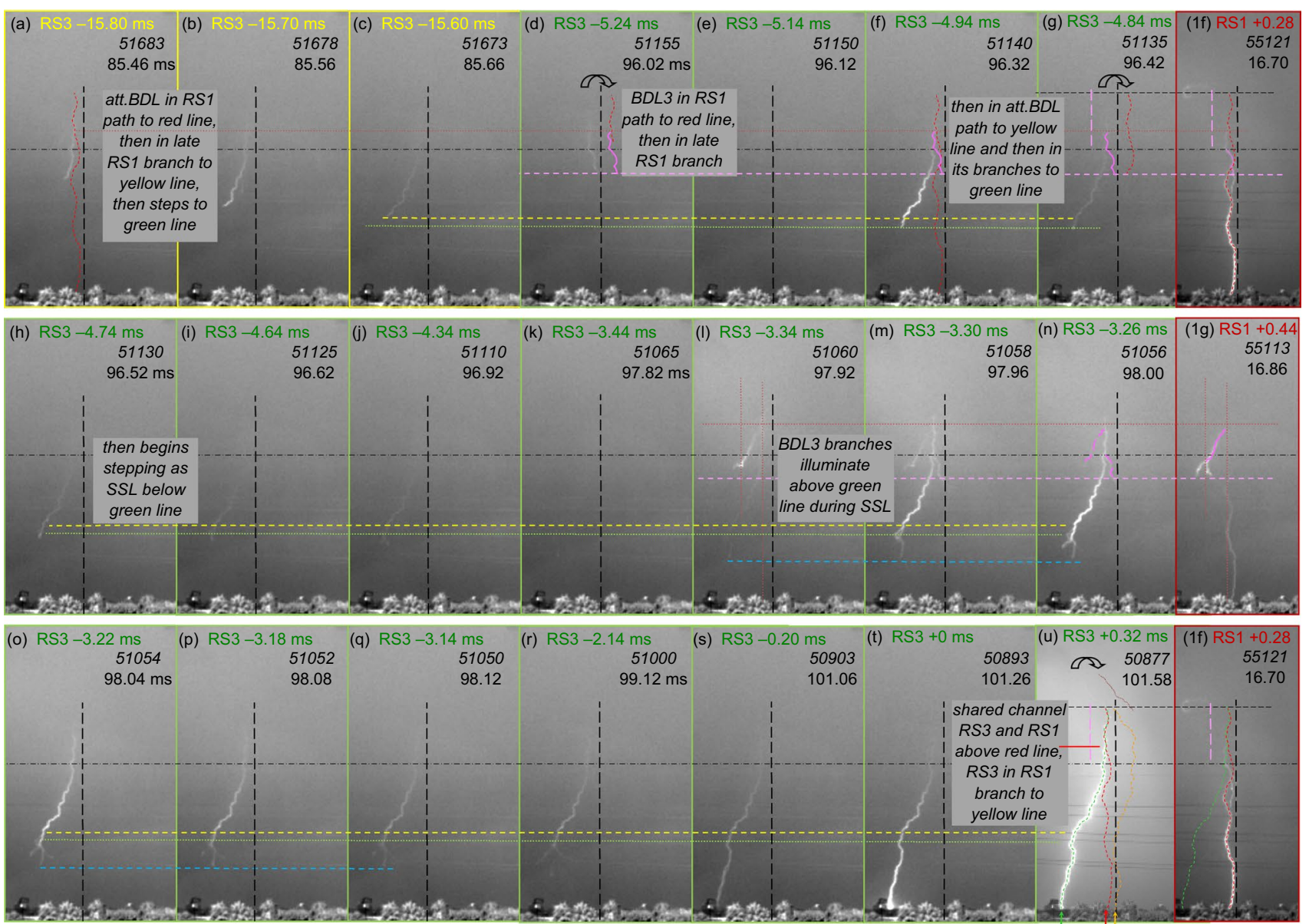

Fig. 10 Example of branch mode-branched dart leader type of SSL inception, third stroke of flash on 14 August 2011, at 2133:56 UT. As shown in Fig. 8, times at top are relative to the first frame of each RS, frame number is in italics, and time (in ms) after largest IB pulse is given (black text). Vertical and horizontal lines are guides, as shown in Fig. 8. Upward arrows at ground are shown in Fig. 8, with RS3

The fourth stroke of this flash, like the second stroke, involved an SSL inception of the branch mode-initial leader type. The sequence of events that preceded RS2, described above, was essentially repeated prior to RS4 except along a different initial leader path. Key frames from the video data are shown in Fig. 11. The frames in Fig. 11a-f show the dart leader activity that started $78.68 \mathrm{~ms}$ before RS4, visible in the very short channel portion that is shared in RS1 and RS2, and then along the upper part of the RS2 channel. This visible dart leader advance ends $0.36 \mathrm{~ms}$ later (Fig. 11e). About at the time of Fig. 11f, the leader begins advancing as a stepped leader, and the dart leader portion fades. The short tracings in pink and orange in Fig. 11 show shared pieces, including the 'seagull' piece (pink) from RS1 and RS2 and the connecting piece (orange) that appeared at the top of RS2. (For reference, RS2 is shown at the top right; frame $(1 \mathrm{~m})$ is the same as $(\mathrm{m})$ from Fig. 8.) With these shared location added (in green). RS1 path (red curve), RS2 path (orange curve), and RS3 path (green curve) are traced in $\mathbf{u}$. The horizontal guide line (in blue) allows one to see the advance of the SSL through $0.2 \mathrm{~ms}$ (frames in Fig. 10l-q), see text for details of sequences depicted in $\mathbf{a}-\mathbf{u}$

segments, the short piece (traced in light blue) first seen in this stroke at the time of Fig. 11d forms a ' 2 ' shaped piece that is then visible throughout the remaining time before, during, and after RS4. (Note that in Fig. 11d, f, g, the tracings are translated by the arrow length for display.)

After the frame shown in Fig. 11f, most of this remarkably long SSL to RS4 is only intermittently visible in the video data for the next $75 \mathrm{~ms}$, partly due to its path in a rain shaft. Figure 12a shows corresponding E-change and LDAR2 data for the fourth stroke. Unlike the other three SSLs of the flash, this leader was accompanied by many VHF sources located by LDAR2. These sources show the stepped leader propagated mainly horizontally, near $4 \mathrm{~km}$ altitude $( \pm 0.5 \mathrm{~km})$, for at least $40 \mathrm{~ms}$ after the SSL inception and before descending in several major branches to ground. (Note, however, that each branch is represented by only one or two LDAR2 sources.) While in most of the 

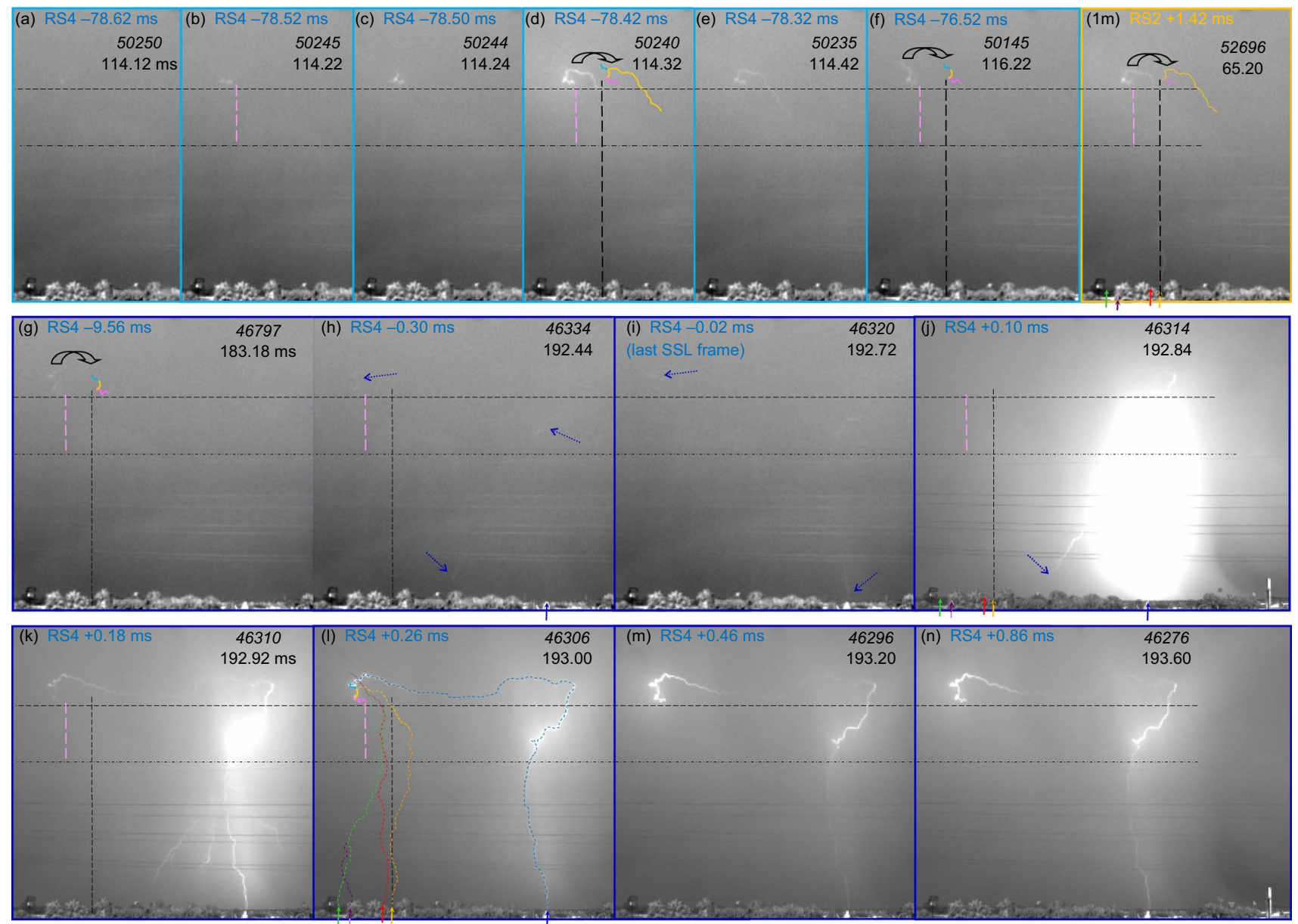

Fig. 11 Example of branch mode-initial leader type of SSL inception, fourth stroke of flash on 14 August 2011, at 2133:56 UT. As shown in Fig. 8, times at top are relative to the first frame of the RS. Each frame number is in italics, with time (in ms) after the largest IB pulse in black text. Vertical and horizontal lines are guides, as shown in Fig. 8. Upward arrows at ground are RS connection locations, as

video data, the horizontal portion of the SSL is obscured, the overlay of LDAR2 sources projected onto the RS4 channel location (see Fig. 7, top left) match very well. The SSL to RS4 is more visible during several brief events, such as the one shown in Fig. 11g beginning $9.6 \mathrm{~ms}$ before RS4, when there is also a large amplitude pulse-train event in the E-change data (Fig. 12a).

About $1 \mathrm{~ms}$ before RS4 (e.g., Fig. 11h, i), the SSL becomes visible near ground, about $3.3 \mathrm{~km}$ to the right of RS2. Although RS4 saturates much of the image near the channel, multiple branches are visible in the $0.2 \mathrm{~ms}$ after RS4 (e.g., Fig. 11j, k). Comparison to the other RS channels shown in Fig. 111 indicates only a short piece of the RS4 channel is shared with RS2. The ' 2 '-shaped piece of this channel also illuminates brightly during multiple M-component re-illuminations (e.g., frames shown in Fig. $11 \mathrm{~m}, \mathrm{n}$ ) after RS4. The interval between RS2 and shown in Fig. 10, with RS4 added in blue. Paths of RS1 (red), RS2 (orange), RS3 (green), and RS4 (blue) are traced with dashed curves. Note the evident rain shaft illuminated by this stroke. The arc across the middle of the images is an intense rainbow, see text for details of the leader progression shown in $\mathbf{a}-\mathbf{n}$

RS4 is 128.96 ms; the interval between RS3 and RS4 is $91.48 \mathrm{~ms}$.

The final SSL of this flash occurs in the fifth stroke, and its inception is by the divert mode (stroke included in Table 3, column 2). Figure 13a-d shows video images for the final $0.82 \mathrm{~ms}$ of this dart leader, traveling along the prior RS3 channel, down to $1.53 \mathrm{~km}$ altitude (green dotted horizontal guide, same as shown in Fig. 10). At this point, $5.50 \mathrm{~ms}$ prior to RS5, the dart leader stops advancing; here, it diverts from the RS3 channel and switches to stepping. The E-change data in Fig. 12b show the train of relatively large amplitude pulses associated with this dart leader abruptly end at the time of Fig. 13d, and the first few stepped leader pulses begin near the time of Fig. 13e. The frames in Fig. 13f-1 reveal the branched SSL advancing to ground for RS5. Figure $13 \mathrm{~m}$, an image just after RS5 (still saturated near the channel), shows 

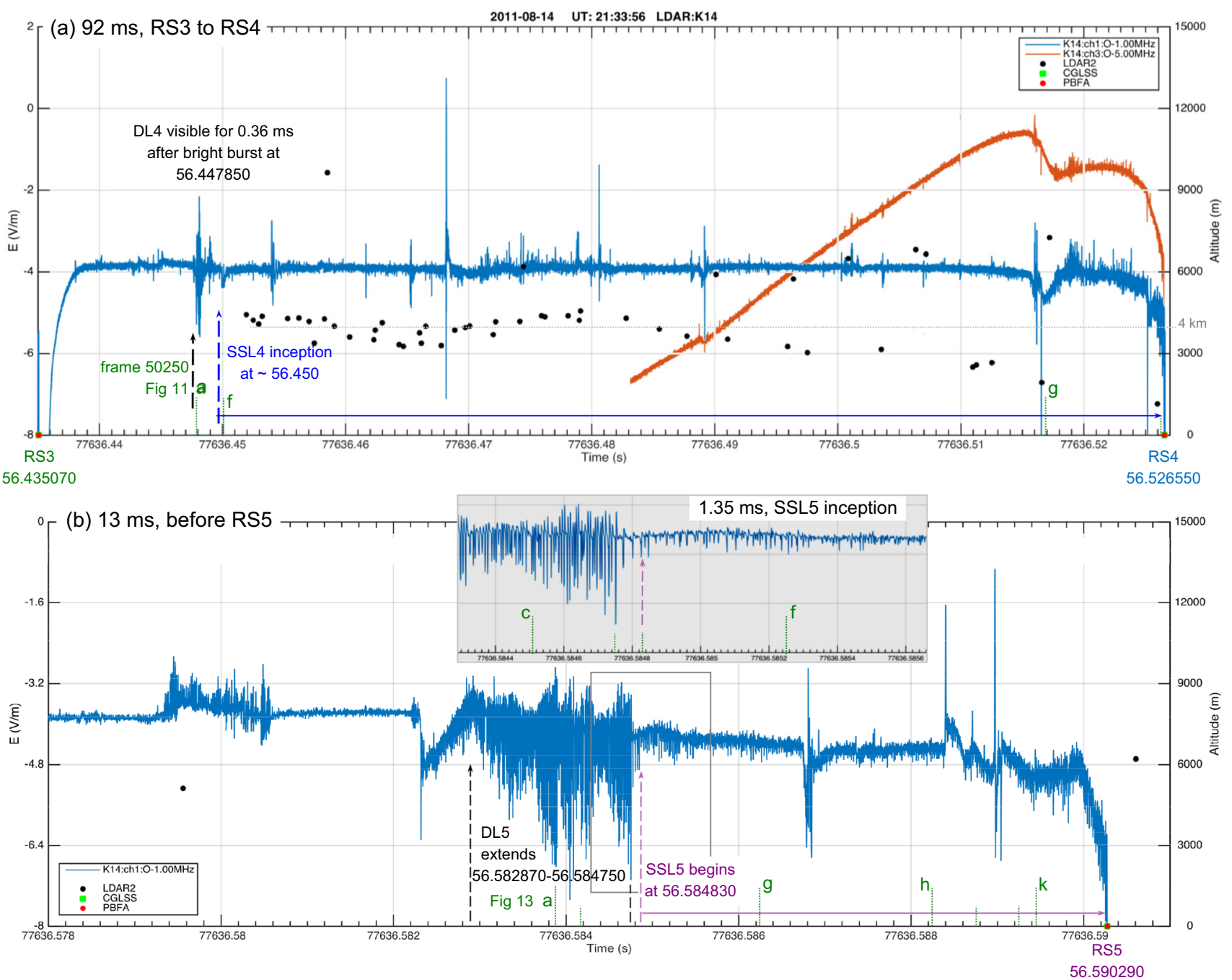

Fig. 12 Time series of E-change data and LDAR2 source altitudes for two subsequent strokes of flash at 2133:56 UT (77636 s past $00 \mathrm{UT}$ ), 14 August 2011. a Leader activity prior to RS4, with SSL inception via branch mode-initial leader type (see also Fig. 11). Large E-change pulses accompany the brief dart leader that begins near $5.5 \mathrm{~km}$ altitude at $78.68 \mathrm{~ms}$ before RS4. This DL4 switches to stepping within about $2.5 \mathrm{~ms}$. LDAR2 sources (black circles) during the SSL advance indicate the leader is between 5 and $3 \mathrm{~km}$ for at least $50 \mathrm{~ms}$ before descending. A bright event that makes the SSL4 system briefly visible in the video data (e.g., Fig. 11, frame g) about $9.6 \mathrm{~ms}$ before RS4 is coincident with a large E-change event. The full RS4 E-change is off scale here (see Fig. 7) in Ch1 data; Ch3 data (red curve) at this K14 site come out of saturation during SSL4,

multiple low-level branches illuminated in the SSL portion of the channel. In Fig. 13n, a comparison of the RS5 and RS3 paths indicates entirely shared channel for these two strokes above the diversion point (level of the green dotted line). The uppermost portion of the RS1 path (red dashed curve) is also shared with RS5 (tracing translated to right for display, as indicated by double arrow). There is no visible shared channel with RS4 in RS5. The interval but are saturated again due to RS4 for the remainder of the flash. b Leader activity prior to RS5, with SSL inception via divert mode (see also Fig. 13). The DL visibly extends along the RS3 channel for $1.88 \mathrm{~ms}$, then switches to stepping at $1.50 \mathrm{~km}$ above ground. The SSL advances for about $5.4 \mathrm{~ms}$ to RS5. Inset plot, including the last of the DL5 advance and the SSL5 inception, shows there is a very brief pause (about $0.08 \mathrm{~ms}$ ) between evident DL pulses and first SSL pulses, in agreement with the video data (Fig. 13, frames d, e). Two medium amplitude bipolar pulses in the $0.08 \mathrm{~ms}$ between end of DL (frame d) and start of SSL (frame e) may be associated with attempted or unseen DL or SSL advance. The full field change to RS5 is off the scale shown here

between RS3 and RS5 is $155.20 \mathrm{~ms}$ and that between RS4 and RS5 is $63.72 \mathrm{~ms}$.

Except that it is not visibly branched, the dart leader before RS5 behaves much like the unsuccessful BDL prior to RS3 and to the successful BDL that switched to a successful stepped leader for RS3. Nearly, the same point is reached by each. However, in this traverse, until it diverts, the dart leader is following a prior RS channel that 


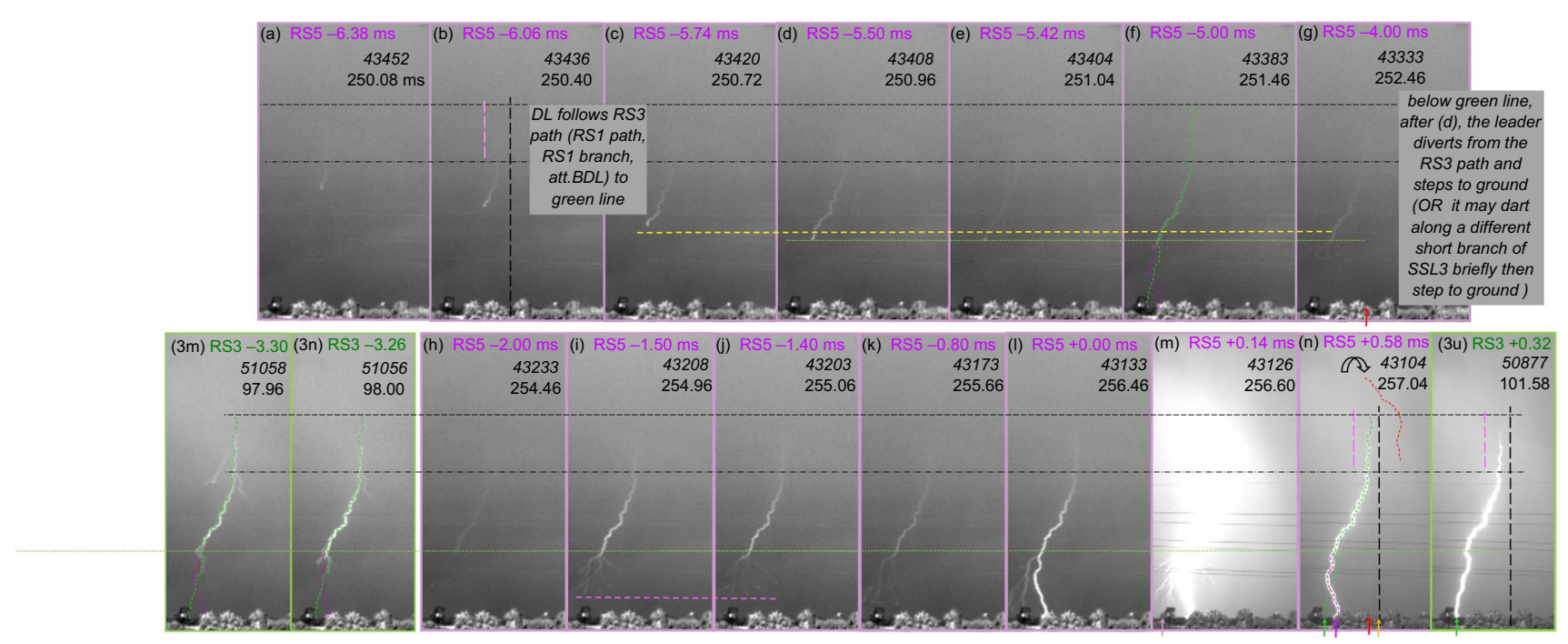

Fig. 13 Example of divert mode of SSL inception, fifth stroke (RS5) of flash on 14 August 2011, at 2133:56 UT. As shown in Fig. 8, times at top are relative to the first frame of the RS, frame number is in italics, and time (in ms) after largest IB pulse is given (black text). Vertical and horizontal lines are guides, as shown in Figs. 8 and 10.

previously ended at the ground. In contrast, prior to RS3, the (branched) dart leaders were following prior branches (of the first stroke) that ended above ground; to continue advancing from that point those branched dart leaders had to switch to stepping.

In Fig. 13, frames labeled 3m, 3n, and $3 u$ are the same, as shown in Fig. 10, repeated to facilitate comparison with the earlier stroke. We note that in this case (like the other divert mode cases), there was multi-branching in the third stroke leader very close to the diversion point, where the switch from DL to SSL occurs later during the fifth stroke. (Recall this is also very close to where the end and switch to stepping of the earlier attempted BDL occurred.) The diversion point (indicated in frames $3 \mathrm{~m}$ and $3 \mathrm{n}$ at times when the entire SSL3 was illuminated 3.26-3.30 ms before RS3) is a veritable 'knot' of branches that stem from the RS1 channel at this location. Thus, an alternative interpretation of the fifth stroke SSL inception could be that it is via the branch mode-that is, stepping begins from the end of a prior unused short branch remaining from the third stroke, more than $150 \mathrm{~ms}$ earlier. However, we favor the divert mode interpretation, because none of the visible prior branches match the RS5 path exactly. The first apparent stepping in this SSL occurs about $120 \mu$ s after the end time of the dart leader advance, which is longer than evident in most branch mode inceptions. The E-change data (Fig. 12b, inset) also show a relatively long pause $(\sim 100 \mu \mathrm{s})$ between the end of the dart leader pulses and the beginning of regular stepped leader pulses.
Upward arrows at ground are shown in Fig. 10, with RS5 location color-coded in purple. RS3 path (green dashed curve) is traced in $\mathbf{n}$. Frames 3m, 3n, and 3u here are shown in Fig. 10, repeated to facilitate comparison, see text for details of sequences depicted in $\mathbf{a}-\mathbf{n}$

The final three strokes of this flash followed the RS5 path to ground. The dart leader to RS6 became visible $87.10 \mathrm{~ms}$ after RS5, and the interstroke interval was $87.56 \mathrm{~ms}$. The entire duration of this exceptional flash example exceeded $570 \mathrm{~ms}$ (e.g., Fig. 7).

\section{Summary and discussion}

In trying to understand why dart leaders do not always follow the prior RS path all the way to ground, it is important to note as a basis that the prior RS path becomes a relatively poor conductor by the time the dart leader begins. This basis is indicated by two facts. First, typical dart leader speeds are $1 \times 10^{7} \mathrm{~m} / \mathrm{s}$ (or less), while typical RS speeds are $1-2 \times 10^{8} \mathrm{~m} / \mathrm{s}$ (e.g., Rakov and Uman 2003). The order-ofmagnitude difference in speeds indicates a substantial difference in the conductivity encountered by the dart leader compared to that of the prior return stroke when traveling on the same path. Second, Shao et al. (1995), using a VHF interferometer operating at 271-277 MHz, found that VHF sources "readily delineated" a "well-defined path" for each dart leader (e.g., see their Figs. 3b, 9b). This well-defined path in VHF is presumably caused by small-scale breakdowns occurring at frequent intervals as the dart leader re-ionizes and travels down the prior RS path. These breakdowns probably indicate that there are numerous small-scale cutoff regions along a prior RS channel which must be bridged across by the advancing dart leader. If such a cutoff occurs at or near a branch point of a prior leader, the possibility exists 
that a branch may be preferred over the previously used main path, thereby creating the possibility for a branch mode SSL inception. Or, if a cutoff is substantial enough, such that no suitable path for dart leader advance is available, then stepped leader advance along an entirely new path might begin, as in the divert mode of SSL inception.

One basic reason why a different branch might be preferred over the previously used main path is charge rearrangement in the cloud due to prior RS current(s) and any interstroke activity. The prior RSs and any in-cloud leader activity occurring before the next dart leader begins can alter the electric field and electric potential in ways that may make a previously used path less attractive for dart leader propagation, while concurrently making a previously developed, but unused branch more attractive for the propagating leader. (This charge rearrangement mechanism is related to the cutoff mechanism proposed by Mazur and Ruhnke (1993, 2014) and discussed in the Introduction.) The fact that earlier branches were cutoff electrically from the descending leader means that they retain their own reservoir of charge and their own potential (e.g., Stolzenburg et al. 2015). Thus, the rearrangement of charge during prior strokes and during interstroke intervals can change the potential in ways that allow dormant, undischarged, or abandoned leader branches to become active, extend, and possibly reconnect to start a new dart leader. It should be obvious that a detailed explanation of how an SSL of either mode develops will require modeling and substantially more information than available in this study; we speculate charge rearrangement will be an important part of that explanation.
Fig. 14 Summary schematic depicting two modes of subsequent stepped leader (SSL) inception after a prior stroke in negative cloud-to-ground (CG) lightning. The prior return stroke channel is solid red in a (panel repeated below itself for sideways reference), with leader starting from the location of the first initial breakdown (IB) pulse. The prior channel location is indicated by the red dotted curve in panels b-e, although only a part of it (shared channel portion) illuminates in these subsequent strokes. Downward dart leader (DL) portions are represented by heavy dashed curves, and stepped leader portions are solid
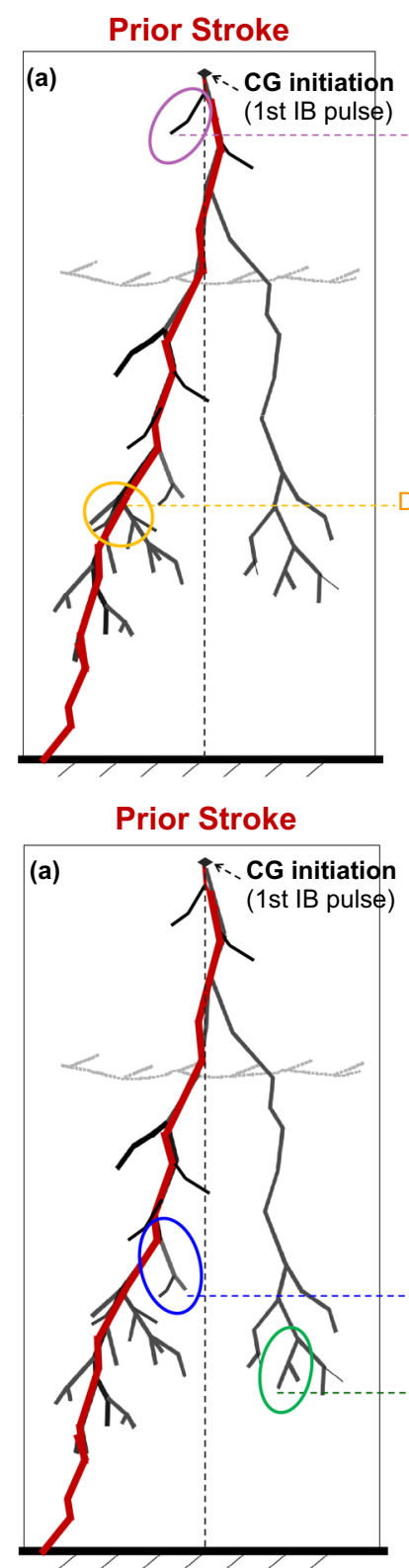

Divert Mode

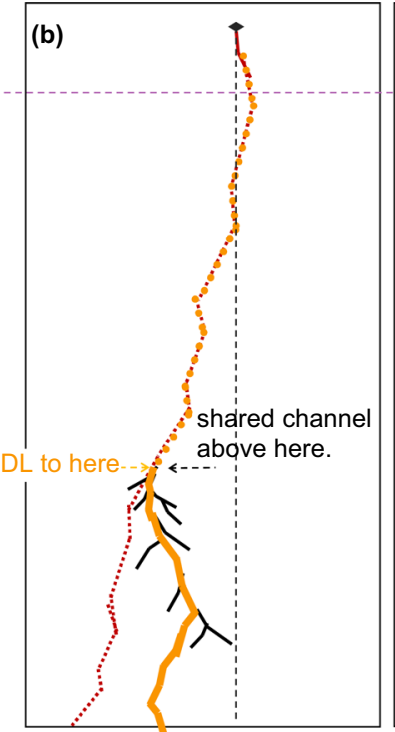

Branch Mode competing leader type

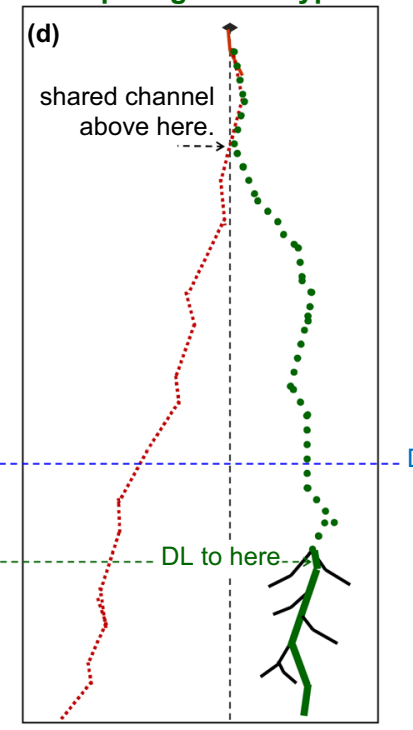

Branch Mode - early leader type

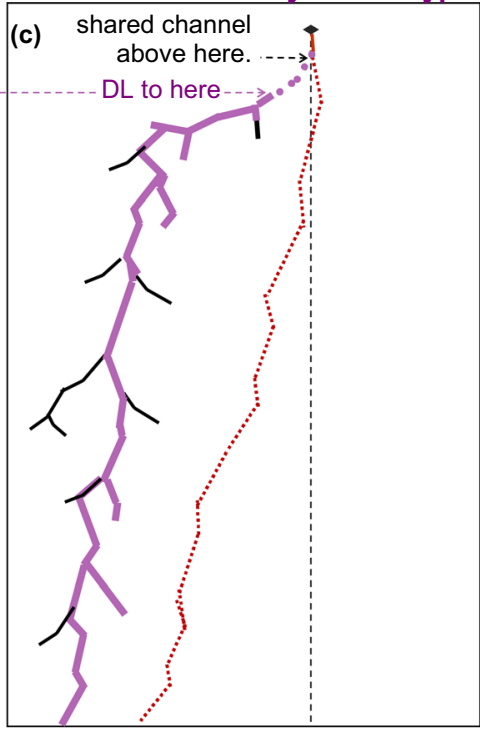

Branch Mode - Branched Dart Leader (BDL) type

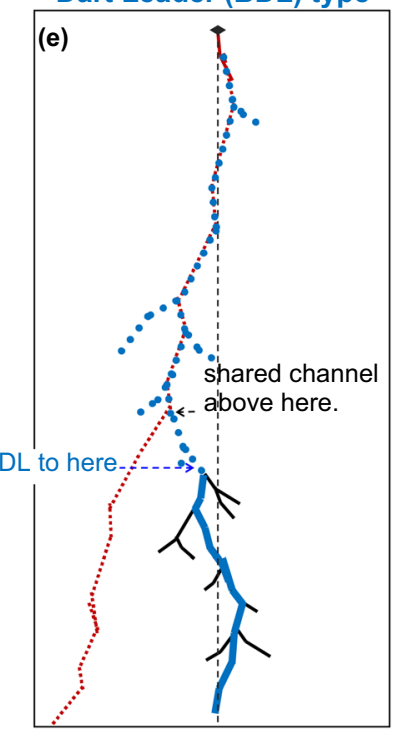


With Fig. 14, we summarize the SSL inception modes in schematic form. This diagram shows the most basic features of the divert mode and of the three types in the branch mode. Channel locations and dart leader form are highlighted; these features are characteristic of the different types but not truly fundamental, that is, they do not determine why the SSL occurs. In the divert mode (Fig. 14b), the dart leader follows the prior channel until the leader switches to a stepped leader that advances to ground. The branch mode manifests in three types (Fig. 14c-e), and in each of these, the dart leader reaches the end of a prior unsuccessful branch and then advances as a stepped leader to ground. The branch mode-early leader type uses a short high branch of the initial leader that developed during the initial breakdown stage of the flash. The branch mode-competing leader type uses a former branch that previously reached mostly to ground but stopped at the time the prior stroke's winning stepped leader reached ground. The branch mode-BDL-type advances as a branched dart leader in several prior branches, reaches the end of a prior unsuccessful branch, then becomes a stepped leader to ground from that end. These SSLs generally require high-speed video data to accurately identify or confirm their inception mode and type, due to the close proximity and concurrence of branches and the brief duration of prior activity along them.

The fundamental difference between the two SSL inception modes is in the type of the leader at the time when it deflects from a prior path. In the divert mode of SSL inception, the subsequent leader deflects from the prior path as a stepped leader. In contrast, in the branch mode of SSL inception, the subsequent leader deflects from the prior path as a dart leader; this dart leader is propagating in a branch (or in several branches) that previously ended above ground, and stepped leader advance starts when the branch's prior end is reached. Unlike the branch mode, the divert mode always has a portion of the dart leader path that has previously carried a return stroke current.

We summarize our observations for the divert mode as follows:

(a) The altitude of the diversion point, where the switch from dart leader to SSL occurs (and corresponding time of SSL advance prior to the RS) varies, but is usually relatively low $(<2100 \mathrm{~m}$ altitude) along the channel. We can discriminate no difference in the prior RS channel at the point where the dart leader pauses and diverts. However, in each of the four visible cases, this diversion point is a major branch-off point and kink. We hypothesize that such multiple branching-off points and kinks of extra tortuosity might cutoff more readily or be more difficult for a later dart leader to pass through. (b) In three divert mode cases, the visible channel to ground has been used only once; in two of these flashes, there is an intervening stroke that uses a different channel and does not pass through the relevant diversion point. However, in the fourth case, the entire visible channel portion has been traversed by a return stroke three times. Thus, channel conditioning by the current flow of multiple prior return strokes may be important but does not preclude the occurrence of the divert mode of SSL inception.

(c) The time interval from the prior (relevant) RS to when the dart leader stops and switches to a stepped leader exceeds $105 \mathrm{~ms}$ in the four visible divert mode cases. The full relevant RS intervals are all greater than $117 \mathrm{~ms}$ and average $164 \mathrm{~ms}$, compared to the average interstroke interval of about $87 \mathrm{~ms}$ for our full set of 488 subsequent strokes. We speculate that such long intervals allow substantial loss of channel conductivity and cutoff to occur, which may contribute to the likelihood of the dart leader diverting from the prior channel.

The fundamental question for the "divert" SSL cases is why does the dart leader pause, divert and switch to stepping? As discussed above, channel conductivity loss seems a key factor, and an increased tendency for more complete cutoff to occur, where the channel splits into many branches may also have a role. The physical reasons that a dart leader would find essentially no conductivity remaining below some point along a former RS channel and would hence need to or prefer to make an entirely new path to ground require further study.

The branch mode of SSL inception is more common, and we categorize it into three types summarized as follows:

(a) The early leader type yields mainly a long SSL portion, much like a first stroke leader; hence, most of the subsequent stroke is along a new channel. These are typically preceded by a long interstroke interval. The dart leader portion is along a path formed near in time and space to the flash initiation, although only a few cases of this type are second strokes. Thus, it seems that charge rearrangement during and after preceding strokes, which can affect the potential distribution near the flash initiation, may be important in the occurrence of this SSL inception type.

(b) The competing leader type results in a stroke that is most similar to a typical (dart leader only) subsequent stroke, except the path of the dart leader portion is along a former 'losing' stepped leader to its end, then the SSL forms the new path to ground. The branch point of the formerly competing leaders is sometimes visible; in such cases, there is visible shared channel among the strokes above the branch point. SSLs of this 
type tend to have the shortest preceding interstroke intervals. In addition, the competing leader branch used in the subsequent stroke is often not illuminated during the prior return stroke. These observations suggest to us that the dart leader in this type is perhaps the most "ready to go" after the prior stroke. The competing, unsuccessful stepped leader was likely cutoff from and not discharged by the prior stroke, and this alternate path is then preferred in the subsequent stroke, perhaps because of charge rearrangement, as discussed above.

(c) The branched dart leader (BDL) type involves a typically bright and fast dart leader propagating along several prior branches at once, sometimes including a prior return stroke channel. However, unlike most strokes that involve BDLs but do use the prior path to ground, these step to ground from the end of a formerly unsuccessful branch. As noted also in Stolzenburg et al. (2014), there are many cases of 'failed' BDLs which exhibit a change to stepping from the ends of branches, but do not reach ground. Similar to the early leader type, charge rearrangement by prior activity may cause the potential distribution to favor new stepped leader propagation from a different branch end, rather than simply having the dart leader reach ground along the former channel. Channel conductivity loss and cutoff are likely factors, also.

We also note that most BDLs do not yield a new ground connection: in Stolzenburg et al. (2014), only 5 of 50 BDL cases were type 'B-then-step' that resulted in a successful stepped leader and return stroke. To further complicate matters, there are cases in which a previously unsuccessful and then stepping branch of a BDL competes with a dart leader branch in the former channel, and in most of those cases, the leader in the former channel wins (so the SSL starts but is unsuccessful). Finally, as shown in Fig. 10, there are many branch-mode SSL inceptions that do not result in a return stroke, because all the leaders fail to reach ground.

The basic question for the branch mode SSL cases is why does this dart leader travel in an unused branch, rather than in the former RS channel? If one could answer this question, then it would be easy to explain that the switch to stepping in these cases occurs because the former leader end is reached; there is no other option for continued advance except via stepped leader propagation. As discussed above, channel conductivity loss and cutoff are likely important. However, more critical factors may be the charge rearrangement by prior strokes and the complicated effects of any interstroke activity and interactions with any remaining leader charge that was not involved in prior strokes.

This study has not revealed why there are these two different modes of SSL inception. The long interstroke intervals in all but the branch mode-competing leader type provide important clues. Not only does a long time interval provide more time for conductivity loss, but there is also more time for interstroke activity. In general, the optical and electromagnetic data show that there is significant in-cloud leader activity in these flashes between strokes. Although we tabulate interstroke interval, a more relevant parameter may be the time since former activity along a channel or leader path, which is difficult or impossible to quantify. The rearrangement of charge during prior strokes and during interstroke intervals can change the potential in ways that allow dormant, undischarged, or abandoned leader branches to become active, extend, and possibly reconnect to start a new dart leader. Finally, it must be obvious that substantial branching of initial leaders, stepped leaders, and dart leaders is crucial to development of SSLs during a multi-stroke CG flash. The extent, direction, and altitude of branching in leaders formed before and after the prior RS are governed generally by the ambient cloud potential and the leader potential, although the mechanism of leader branching is poorly understood.

One flash with four SSL strokes has been shown (Sect. 5) and that flash has examples of both SSL inception modes and of two of the three branch-mode types. Among the 18 multi-SSL flashes in our data set, there are six flashes with more than one SSL inception mode or type identifiable; their existence supports our conclusion herein that it is not the pre-flash charge structure alone which governs SSL inception. Many aspects of subsequent stroke conditions at the time when the dart leader starts are likely factors: channel conductivity loss and cutoff; charge rearrangement before, during, and after prior RSs, including rearrangement by various interstroke activities; and the existence of charge remaining on early leaders that were not discharged or involved in prior strokes.

\section{Conclusions}

Most subsequent return strokes in cloud-to-ground lightning flashes are preceded only by a dart (or dart-stepped) leader that travels along the prior RS channel all the way to ground. Nonetheless, this study supports numerous prior works (e.g., Kitagawa et al. 1962; Rakov et al. 1994; Willett et al. 1995; Valine and Krider 2002; Qie et al. 2005; Saba et al. 2006) of multiple ground connecting flashes by showing that subsequent stepped leaders (SSLs) are not a rare occurrence in CG lightning. Out of 488 subsequent strokes in our video data set for 139 natural flashes in Florida, 88 (18\%) involved a stepped leader during part of the leader propagation to ground. In 82 cases, subsequent return strokes were immediately preceded by stepped leaders to a new ground location, while another 6 subsequent return strokes were preceded by stepped-to-dart leaders (e.g., Stolzenburg et al. 2013b) to a 
prior ground location. Overall, 52\% (61) of the 118 multiple RS flashes had at least one successful SSL. Among the second-order strokes, $36 \%$ involved a successful SSL, while $27 \%$ of the 300 strokes of order 2nd through 4th involved an SSL. Occurrence statistics for the high-speed video data set are shown in Fig. 1, and ground connection location counts are given in Table 1.

The main aim of this work has been to describe two modes in which stepped leaders involved in subsequent strokes are found to begin. All the SSLs apparently start when a dart leader stops advancing, based on high-speed video and E-change data; hence, we suggest they should be correctly termed "dart-then-stepped" leaders. The two basic SSL inception modes essentially separate the cases into those which propagate as a dart leader in a former RS main channel and 'divert' from it as stepped leader, and those which do not. In this latter 'branch' mode, the dart leader reaches the end of a prior unsuccessful branch and then propagates further as a stepped leader. We have subdivided the branch mode into three types based on whether the dart leader branch travels to the end of (a) an initial or early leader (b) a long competing stepped leader, or (c) an unsuccessful dart leader branch. Among the 40 cases in which the inception mode is identifiable in the video data, $34(85 \%)$ are of the branch mode. The best evidence for the SSL inception mode exists for 26 strokes in which the change from dart leader to SSL is visible in the video data, and 22 of these are branch mode cases. The two SSL inception modes and the three branch mode types can occur in different strokes of the same flash, an example of which we describe in Sect. 5 (Figs. 7, 8, 9, 10, 11, 12, 13).

We have summarized our two modes of SSL inception in schematic form in Fig. 14, based primarily on video evidence for the 26 cases in which it is visible. Table 2 also lists preceding interstroke interval statistics for the SSL strokes, by mode and type. In general, interstroke intervals (ISIs) are relatively long for strokes involving an SSL, averaging about $94 \mathrm{~ms}$. For the entire set of 488 subsequent strokes (including the 88 SSL strokes), the mean and median ISI are $87 \mathrm{~ms}$ and $65 \mathrm{~ms}$ (Fig. 1c). The amount of shared channel and duration of SSL advance vary widely among the types.

It is worth emphasizing that in many cases, the only way to determine the mode of SSL inception may be from highspeed video observations. Return stroke channel overlap and duration or altitude from which the leader propagates as an SSL before the RS (to a new ground location) are indicative, but are not deterministic. The close proximity and concurrence of many branches, along with the brief duration of prior activity along some branches, mean that one could not reliably identify the SSL inception mode or type using time-of-arrival lightning mapping data.

Both SSL inception modes described in this work indicate that cutoff has occurred along the prior channel or leader, making a new air breakdown path necessary and/or preferred to the previously used channel. The atypically long interstroke intervals support the idea that excessive conductivity loss along the channel and leader branches is important for SSL development. In addition, the finding that there are two distinct inception modes and three different types of one mode, sometimes within the same flash, indicates that the charge rearrangement which occurs before, during, and after preceding RSs is critical to the production of SSLs. The many visibly active branches and extensive leader activity during the sometimes long interstroke intervals support the ideas that undischarged leaders and interstroke charge rearrangement are important to the development of SSLs. A physical mechanism of subsequent stepped leader inception deserves explicit modeling, and our findings suggest that it should incorporate conductivity loss and cutoff effects along prior leader and channel paths, in addition to effects on electric field and electric potential due to the rearrangement of charge by interstroke activity and the remaining charge on the prior leader paths.

Acknowledgements We appreciate the assistance with data collection by Nadee Karunarathna, Lauren Vickers, Chris Maggio, and Clay Conn. The equipment and expertise generously provided by Tom A. Warner and Richard E. Orville were vital and greatly appreciated. The sensor site hosts are gratefully acknowledged for their help. Research data used in this paper are available directly from the corresponding author (mstolzen@olemiss.edu). This project was supported by the US National Science Foundation (Grants AGS-1427734 and AGS-1110030 to UM, and AGS-0813672 to TAMU).

Open Access This article is distributed under the terms of the Creative Commons Attribution 4.0 International License (http://creativeco mmons.org/licenses/by/4.0/), which permits unrestricted use, distribution, and reproduction in any medium, provided you give appropriate credit to the original author(s) and the source, provide a link to the Creative Commons license, and indicate if changes were made.

\section{References}

Anderson RB, Eriksson AJ (1980) Lightning parameters for engineering application. Electra 69:65-102

Ballarotti MG, Saba MMF, Pinto O Jr (2005) High-speed camera observations of negative ground flashes on a millisecond-scale. Geophys Res Lett 32:L23802. https://doi.org/10.1029/2005G L023889

Campos LZ, Saba MM, Warner TA, Pinto O Jr, Krider EP, Orville RE (2014) High-speed video observations of natural cloud-to-ground lightning leaders: a statistical analysis. Atmos Res 135-136:285305. https://doi.org/10.1016/j.atmosres.2012.12.011

Heckman S (1992) Why does a lightning flash have multiple strokes? Dissertation, Massachusetts Institute of Technology

Karunarathne S, Marshall TC, Stolzenburg M, Karunarathna N, Vickers LE, Warner TA, Orville RE (2013) Locating initial breakdown pulses using electric field change network. J Geophys Res Atmos 118:7129-7141. https://doi.org/10.1002/jgrd.50441 
Kitagawa N, Brook M, Workman E (1962) Continuing currents in cloud-to-ground lightning discharges. J Geophys Res 67(2):637647. https://doi.org/10.1029/JZ067i002p00637

Krider EP, Weidman CD, Noggle RC (1977) The electric field produced by lightning stepped leaders. J Geophys Res 82:951-960. https://doi.org/10.1029/JC082i006p00951

Malan DJ, Schonland BFJ (1951) The electrical processes in the intervals between the strokes of a lightning discharge. Proc R Soc Lond Ser A Math Phys Sci 206(1085):145-163

Marshall T, Stolzenburg M, Karunarathna N, Karunarathne S (2014) Electromagnetic activity before initial breakdown pulses of lightning. J Geophys Res Atmos 119:12558-12574. https://doi. org/10.1002/2014JD022155

Mazur V, Ruhnke LH (1993) Common physical processes in natural and artificially triggered lightning. J Geophys Res 98:12913-12930

Mazur V, Ruhnke LH (2014) The physical processes of current cutoff in lightning leaders. J Geophys Res Atmos 119:2796-2810. https ://doi.org/10.1002/2013JD020494

Murphy MJ, Cummins KL, Demetriades NWS, Roeder WP (2008) Performance of the new four-dimensional lightning surveillance system (4DLSS) at the Kennedy Space Center/Cape Canaveral Air Force Station complex. In: 13th Conf on aviation, range, and aerospace meteorology, New Orleans, LA

Qie X, Zhang T, Chen C, Zhang G, Zhang T, Wei W (2005) The lower positive charge center and its effect on lightning discharges on the Tibetan Plateau. Geophys Res Lett 32:L05814. https://doi. org/10.1029/2004GL022162

Rakov VA, Uman MA (1990) Waveforms of first and subsequent leaders in negative lightning flashes. J Geophys Res 95(D10):16561-16577

Rakov VA, Uman MA (2003) Lightning: physics and effects. Cambridge University Press, Cambridge (ISBN:0521583276)

Rakov VA, Uman MA, Thottappillil R (1994) Review of lightning properties from electric field and TV observations. J Geophys Res 99(D4):10745-10750

Saba MMF, Ballarotti MG, Pinto O (2006) Negative cloud-to-ground lightning properties from high-speed video observations. J Geophys Res 111:D03101. https://doi.org/10.1029/2005JD006415

Shao XM, Krehbiel PR, Thomas RJ, Rison W (1995) Radio interferometric observations of cloud-to-ground lightning phenomena in Florida. J Geophys Res 100(D2):2749-2783. https://doi. org/10.1029/94JD01943
Stolzenburg M, Marshall TC, Karunarathne S, Karunarathna N, Warner TA, Orville RE, Betz H-D (2012) Strokes of upward illumination occurring within a few milliseconds after typical lightning return strokes. J Geophys Res 117:D15203. https://doi. org/10.1029/2012JD017654

Stolzenburg M, Marshall TC, Karunarathne S, Karunarathna N, Warner TA, Orville RE (2013a) Competing and cut-off leaders before "upward illumination" type lightning ground strokes. J Geophys Res Atmos 118:7182-7198. https://doi.org/10.1002/jgrd.50512

Stolzenburg M, Marshall TC, Karunarathne S, Karunarathna N, Warner TA, Orville RE (2013b) Stepped-to-dart leaders preceding lightning return strokes. J Geophys Res Atmos 118:9845-9869. https ://doi.org/10.1002/jgrd.50706

Stolzenburg M, Marshall TC, Karunarathne S, Karunarathna N, Vickers LE, Warner TA, Orville RE, Betz H-D (2013c) Luminosity of initial breakdown in lightning. J Geophys Res Atmos 118:2918 2937. https://doi.org/10.1002/jgrd.50276

Stolzenburg M, Marshall TC, Karunarathne S, Karunarathna N, Orville RE (2014) Branched dart leaders preceding lightning return strokes. J Geophys Res Atmos 119:4228-4252. https://doi. org/10.1002/2013JD021254

Stolzenburg M, Marshall TC, Karunarathne S, Karunarathna N, Orville RE (2015) An M-component with a concurrent dart leader traveling along different paths during a lightning flash. J Geophys Res Atmos 120:10267-10284. https://doi.org/10.1002/2015JD023417

Valine WC, Krider EP (2002) Statistics and characteristics of cloud-toground lightning with multiple ground contacts. J Geophys Res 107(D20):4441-4449. https://doi.org/10.1029/2001JD001360

Willett JC, Le Vine DM, Idone VP (1995) Lightning-channel morphology revealed by return-stroke radiation field waveforms. J Geophys Res 100(D2):2727-2738

Williams ER (2006) Problems in lightning physics: the role of polarity asymmetry. Plasma Sources Sci Technol 15:S91-S108

Williams E, Heckman S (2012) Polarity asymmetry in lightning leaders: the evolution of ideas on lightning behavior from strikes to aircraft. J Aerosp Lab 5:1-8

Publisher's Note Springer Nature remains neutral with regard to jurisdictional claims in published maps and institutional affiliations. 